\title{
Assessment of Climate change Over Sistan-and- Baluchestan Province of Iran using CMIP6 GCMs; In terms of Precipitation and Surface Air Temperature
}

\author{
Nafiseh Pegahfard ( $\sim$ pegahfar@inio.ac.ir) \\ Iranian National Institute for Oceanography and Atmospheric Science https://orcid.org/0000-0003- \\ 4885-7428
}

\section{Research Article}

Keywords: Climate change, Precipitation, Surface air temperature, Sistan-and-Baluchestan Province, CMIP6-GCMs, historical run, SSP5-8.5, SSP3-7.0

Posted Date: January 18th, 2022

DOI: https://doi.org/10.21203/rs.3.rs-1252589/v1

License: (c) (i) This work is licensed under a Creative Commons Attribution 4.0 International License.

Read Full License 
1 Assessment of climate change over Sistan-and-Baluchestan Province of Iran using CMIP6

2 GCMs; in terms of precipitation and surface air temperature

3 Nafiseh Pegahfar*, Assistant Professor, Iranian National Institute for Oceanography and Atmospheric Science,

4 Research center of Atmospheric Sciences,

5 E-mail: pegahfar@inio.ac.ir; Telephone.: +98-021-66944873; Tax: +98-021-66944869,

\section{Abstract}

Information of probable change in a regional climate system can play an important role in the government's policies. The present study investigates the climate variations over the Sistan-and-Baluchestan Province, the second biggest province of Iran with scarce direct observations, in basis of surface air temperature and precipitation. To this aim, three datasets of (I) in-situ data, (II) gridded data from Climatic Research Unit (CRU, in 19792020), and (III) outputs of historical runs (during 1979-2020) and simulations under the SSP5-8.5 and SSP3-7.0 scenarios (in 2021-2050) of twenty-seven Global Climate Models (GCMs) from the latest Coupled Model Intercomparison Project (CMIP6) were utilized. The climatic analysis was conducted in three steps of (I) evaluation of models' performance comparing with CRU data in 1979-2020, (II) rank the models based on Technique for Order Preference by Similarity to Ideal Solution (TOPSIS) in Multi-Criteria Decision Making (MCDM) technique including eight metrics and (III) analysis of performance of the high-ranked models for 2021-2050. Results showed that CMIP6-GCMs generated lower satisfactory and consistency in simulating precipitation than temperature. The three models of CESM2-WACCM-FV2, MPI-ESM1-2-LR and IITM-ESM (MPIESM1-2-LR and UKESM1-0-LL and ACCESS-CM2) outperformed the others in simulating temperature (precipitation), while the MIROC6 (MIROC-ES2L) model performed the weakest. The MPI-ESM1-2-LR, UKESM1-0-LL and ACCESS-CM2 models achieved the highest rank for the both climate variables. Regarding the high-ranked models, analysis of the CMIP6-GCMs for 2021-2050 showed that the increase of 2.5-3.4 (2.2-3.1) $\mathrm{K}$ for the maximum temperature in SSP5-8.5 (SSP3-7.0) scenario is probable. Both scenarios showed an increasing (decreasing) trend for temperature (precipitation) in 
the future. Conclusively, the considered area will experience a remarkable increase in temperature and significant decrease in precipitation amount. It should be noted that the results from the global models will be exacerbated by any mistake in policy making.

4 Keywords: Climate change, Precipitation, Surface air temperature, Sistan-and-Baluchestan

5 Province, CMIP6-GCMs, historical run, SSP5-8.5, SSP3-7.0

\section{1. Introduction}

7 One of the key issues of concern at present is climate change, because of its relation to human

8 survival, agriculture, food security, ecosystems, and social economy (Donnelly et al., 2017;

9 Quispe-Ccalluari et al. 2018; Christidis et al. 2019; Huang et al. 2019; Liu et al. 2019; Wen et al.

10 2019; Ahmed et al. 2021). Climate change has visibly raised climate extremes, challenged

11 human society and resulted in dramatic increases in international migration (Kaczan et al. 2020;

12 Sharafati et al. 2020; Beine et al. 2021), which can double the consequences of climate change.

13 Precipitation and drought extremes highly influence the fields of transportation and water

14 resource management, especially in a region with vast landmass and complex terrain (Barry et al.

15 2018; Cardoso Pereira et al. 2020; Lun et al. 2021; Samantaray et al. 2021). Sensitivity of water

16 resources and agriculture systems to the climate change (Xu et al. 2015) clarifies the essence of

17 assessment of climate change effects on a regional scale (Zamani et al. 2019). Concerning the

18 significant effect of climate change on water resource variables (Duan and Mei 2014) and also

19 the increase of about $0.85^{\circ} \mathrm{C}$ in temperature in recent decades (Zhao et al., 2020), it is imperative

20 to simulate climate variables, especially in developing countries with complex topography such

21 as multi-climate country of Iran.

One of the most important tools for understanding climate and quantitative prediction is

23 Global Circulation Models (GCMs). Koutroulis et al. (2016) found high accuracy performance of

24 GCMs in climate projection. The Coupled Model Intercomparison Project (CMIP) was

25 established by the World Climate Research Programme to make easier comparisons across

26 different models (Eyring et al. 2016; Baker and Huang 2014). The added value of CMIP6

27 models, comparing to the previous version of CMIP models, can be found as (a) including socio-

28 economic pathways in CMIP6 scenarios, (b) acting in coordination with CMIP5 scenarios 
1 premises (O’Neill et al. 2014), and (c) CMIP6 updates due to its focusing on biases, processes, and feeds of climate models for the development and support of the inter-comparison model

3 (Heinze et al. 2019). Higher horizontal resolutions and considering more complicated processes 4 in CMIP6 models, comparing with CMIP5 models, led to better performance of CMIP6 (Lun et 5 al. 2021). Based on Jiang et al. (2016) findings, topography affects the simulations of GCMs, 6 especially for precipitation, and GCMs perform differently in different regions. This implies that 7 GCMs' simulations should be assessed for each area. Hence, a great deal of researches has been 8 conducted to investigate the ability of CMIP6-GCMs in various parts of the world. For example, 9 Gao et al. (2018) and Lun et al. (2021) assessed the GCMs performance for precipitation and 10 temperature from CMIP5 to CMIP6 over the Tibetan Plateau and found better performance of 11 CMIP6 than CMIP5. Xin et al. (2020) compared CMIP6 and CMIP5 simulations of precipitation 12 in China and the East-Asian summer monsoon and concluded that CMIP6 models had improved 13 the skill scores in climatological patterns relative to previous models of the CMIP5 because of 14 the smallest biases of sea surface temperature in CMIP6 models. Luo et al. (2021) addressed the 15 capability of CMIP6 models in simulating extreme precipitation in China and reached the higher 16 skill of CMIP6 in simulating the frequency distribution of daily precipitation intensity and 17 extreme precipitation amount. In their research, CMIP6 models' ability was not the same for the 18 whole of the China. They also found that the bias still existed in simulating consecutive dry days. 19 Ngoma et al. (2021) employed 15 CMIP6-GCMs and found the best performance in GFDL20 ESM4 model for rainfall over the Uganda during 1981-2014. GCMs have been also used for 21 climate analysis in Iran. In the west and southwest of Iran, Zamani and Berndtsson (2019) 22 examined twenty CMIP5 GCMs and reached different best and weakest climate models in 23 different parts of the selected area. Katiraie-Boroujerdy et al. (2019) examined the ability of five 24 CMIP5 GCMs for simulating precipitation over Iran and ranked them. Miri et al. (2021) used 25 four CMIP5 GCMs to study the temperature variability in the future decades (2015-2059) and 26 found them in parallel with the temporal variations of temperature in the present period and 27 reached the highest temperature variability in winter and somehow in the autumn, mostly in the 28 mountainous areas of Iran. They also predicted that in most parts of Iran, the air temperature 29 would have an increasing tendency in future decades in all four seasons of the year. Zarrin and 30 Dadashi Roudbari (2020), using three CMIP6-GCMs, predicted the average temperature 3 
1 anomaly of more than $2{ }^{\circ} \mathrm{C}$ in 9 months of the year, and less than $2{ }^{\circ} \mathrm{C}$ in January, November and

2 December for the next century. They also showed that the highest monthly temperature change

3 rate was observed in the cold period of the year in the mountainous regions. In addition, Zarrin

4 and Dadashi-Roudbari (2021a) studied five CMIP6-GCMs to project future precipitation changes

5 in Iran and found that the present bias in the region affected by Asian summer monsoon is about

$610 \%$. Hong et al. (2021) assessed the future projections of precipitation based on twenty-four

7 CMIP6-GCMs and showed that heavy rainfall will be more prominent in the western and

8 southwestern parts of Iran by 2100. In contrast, Zarrin and Dasdashi-Rodbari (2021b), based on

9 the five CMIP6-GCMs of GFDL-ESM4, IPSL-CM6A-LR, MPI-ESM1-2-HR, MRI-ESM2-0 and

10 UKESM1-0-LL, found that the consecutive dry days in Iran will increase by a maximum of 26.4

11 days under the SSP5-8.5 scenario for the Lake Urmia, located in the northwest of Iran in the

12 period 2061-2100, while the consecutive wet days will decrease there. In spite of the

13 improvement of the CMIP6 models comparing with the previous versions of CMIP models, but

14 the above paradox proves Zamani et al. (2020) findings who believed that it is necessary to

15 assess CMIP6-GCMs performance in simulating the present and past climate in each region

16 using some reference data. In this way, GCM's capability and precision will be determined

17 (Pörtner et al. 2019) and the uncertainty of their simulation for different climate variables will be

18 appeared (Lun et al. 2021).

Sparsity of meteorological stations, especially in areas with complex topography, makes gridded-observational dataset as the other solution to observational weather and climate data. In

21 addition, availability and accessibility of these datasets together with their good spatial coverage

22 and high spatial and temporal resolution covering several decades make them as a metric for

23 assessment of historical simulations of climate models to evaluate their skills and certainty for

24 future projection.

25 The Sistan-and-Baluchestan Province, located in the southeast of Iran with the sparsity of 26 stations and limited time duration for data recording, has been affected increasingly by the 27 extreme events (tropical cyclones, extreme precipitation and drought) due to climate change. 28 Lack of research studies in perspective of climate change in this area, especially based on GCMs; 29 prevents to give a definite reason for climate change in this province. The extensive province of 4 
1 Sistan-and-Baluchestan has climate diversity. The five factors of atmospheric humidity,

2 precipitation, temperature, sunlight, wind and thunder influence the climate characteristics in this

3 province, respectively (Saligeh et al. 2008). Proximity to Oman Coasts plays a dominant role in

4 more humid and cloudy weather in the south of the province, while windy-dusty weather is the

5 major characteristic of the northern and eastern part of the province. Distance from

6 Mediterranean cyclone trajectory and dominance of subtropical high-pressure systems (Raziei et

7 al. 2007) made the northern and central parts of this province more prone to drought. Zare

8 Abianeh et al. (2015) showed that Sistan-and-Baluchestan Province has experienced frequent,

9 intense and medium droughts in annual and seasonal time scales. Podineh et al. (2015) expressed

10 that complex topography in Sistan-and-Baluchestan Province led to little improvement in

11 precipitation estimation. Recently, policymakers have engaged in developing adaptation

12 alternatives for Sistan-and-Baluchestan Province. Therefore, determining its main climate

13 features and projecting the probable climate change over this area in the future is of great

14 significance.

15 The main goal of this research is to investigate climatology, long-term trend and inter-

16 annual variability in terms of surface air temperature and precipitation over the Sistan-and-

17 Baluchestan Province, based on CMIP6-GCMs and Multi-Criteria Decision Making (MCDM)

18 technique. The principal aim of this research is to reach the probable change of climate for the

19 three next decades in this area. Following, this paper represents the study area, data and methods

20 in section 2. Results of CMIP6-GCMs performance evaluation (from 1979 to 2050 in two time

21 slices of 1979-2020 and 2021-2050) will be described in section 3. Finally, the conclusion will

22 be presented in section 4 .

\section{2. Materials and Methods}

\section{$24 \quad 2.1$. Study area}

25 The province of Sistan-and-Baluchestan as the second largest province of Iran with strategic

26 commercial and transit position is already experiencing consecutive droughts and floods which

27 lead to socio-economic effects. For example, agriculture and horticulture (especially tropical

28 fruits) of this area have been affected. It is noteworthy that in some parts of this province, people 5 
1 have to travel about $4 \mathrm{Km}$ to get drinking water. The only ocean port of Iran, Chabahar Port, is in

2 this province. The Chabahar Port is the only place that has experienced the three extreme events

3 of tropical cyclone (Tropical Cyclone Gonu (in June 2007), Phet (in May and June 2010) and

4 Shaheen (in September and October 2021)). Pegahfar (2021) showed that the number of

5 intensified tropical cyclone forming over the northwest of Indian Ocean might increase in the

6 future. This implies that this region is vulnerable to be affected by tropical cyclone. Recently,

7 after ten years, forming a new tropical cyclone naming Shaheen proved this hypothesis. Because

8 more than half of the population of this province is rural and nomadic, significant parts of rivers'

9 area, rangeland and wetlands in this province have been violated. In addition, excessive

10 abstraction of groundwater has caused land subsidence and fissures. This led to large-scale

11 consolidation (from a Persian-language article in a local journal). Therefore, decrease of water

12 sinking into the ground and its absorption in the aquifers increases the probability of floods in

13 this region containing remote villages. The consequence of these man-made damages may

14 intensify the climate change in this area. For a strategic governmental decision, information

15 about climate variability of temperature and precipitation in this area will be extremely valuable.

16 The selected area, Sistan-and-Baluchestan Province, has been depicted in Figure 1, which

17 is limited from 58 to $64^{\circ} \mathrm{E}$ and from 25 to $32^{\circ} \mathrm{N}$. It has a complex topography of low coastal area

18 in the south to peaks of around $2000 \mathrm{~m}$ above sea level in the northern part. However, the

19 tropical-arid weather is dominant in the most part of this province, but it includes multi-climate

20 regions of mountainous, forested and swampy areas in some places. Complexity of the terrain,

21 scarce of the cities, and the sparsity of in-situ observations make this area as a challenging region

22 for climate research. Hence, this area provides a great opportunity for climate research and

23 evaluation of twenty-seven CMIP6-GCMs performance.

\section{2.2. Data}

25 In this study, two meteorological parameters of surface air temperature and precipitation have 26 been investigated from the perspective of climate change over the southeast of Iran. To this aim,

27 three datasets have been used, including (I) in-situ observational data, (2) gridded observational 28 data from the Climatic Research Unit (CRU), and (3) outputs of CMIP6-GCMs. Each dataset has 29 been described separately as below. 


\subsubsection{In-situ data}

2 Here, measured surface air temperature and precipitation data from thirteen weather stations in

3 the selected province have been used. The principal features of each station have been listed in

4 Table 1. All stations work until the end of January 2020. Location of the stations has been

5 depicted in Figure 1. The incorporated stations recorded 3-hourly surface air temperature and 6-

6 hourly precipitation. All data were objected to quality control filters by Iran Meteorological

7 Organization. All stations started measuring meteorological variables at the beginning of the 8 month, so data in all days of months were available.

\section{$9 \quad$ 2.2.2. CRU data}

10 Sparse in-situ data led to use gridded observational dataset as the other estimate. To this aim, 11 near surface air temperature and precipitation data from CRU Time-Series (TS) version 4.05

12 have been used (https://crudata.uea.ac.uk/cru/data/). The CRU datasets, containing station-based 13 gridded data, have been widely utilized to correct reanalysis data sets (Weedon et al. 2014; Li et 14 al. 2020). Here, monthly mean of surface air temperature and precipitation from the CRU dataset 15 with 0.5-degree resolution in 1970-2020 period have been used.

\section{$16 \quad$ 2.2.3. CMIP6 GCM models}

17 The simulated surface air temperature and precipitation using GCMs extracted from CMIP6, 18 under the high end climate scenario of the shared socio-economic pathway (SSP5-8.5) and the 19 mid-range scenario (SSP3-7.0) from 2021 to 2050 and using historical runs (during 1979-2020), 20 have been used in this research. To extend the period of historical runs to 2020, data from the 21 first six years of the related models from the SSP5-8.5 scenario have been used (similar to Doyle 22 2020). The name and description of the models for each parameter have been listed in Table 2.

\section{2.3. Methodology}

24 Here, eight performance indicators have been used to evaluate the CMIP6-GCMs ability in 25 estimating surface air temperature and precipitation over the Sistan-and-Baluchestan Province. 26 Ranking the models' performance has been done using multi-criteria decision making method 27 (MDCM) technique. The metrics and applied MCDM method have been described as below, 28 respectively. 


\section{$1 \quad$ 2.3.1. Evaluation metrics}

2 Eight indicators of Bhattacharya Distance (BD), Fourth Root Mean Quadrupled Error 3 (R4MS4E), Kling-Gupta Efficiency (KGE, Gupta et al., 2009), Mean Absolute Error (MAE), 4 Nash Sutcliffe Efficiency (NSE, Nash and Sutcliffe, 1970), Root Mean Square Error (RMSE), 5 Skill Score (SS) and Symmetric Uncertainty (SU) have been considered as performance

6 indicators. These error metrics have been used in the previous studies (BD: Anil et al. 2021; 7 R4MS4E: Dehghani et al. 2014; KGE: Nashwan and Shahid, 2020; MAE: Collados-Lara et al. 8 2018; NSE: Ghalami et al. 2021; R2M: Khadka et al. 2021; SS: Keellings 2016 and SU: Homsi 9 et al. 2020). The expression of these error indicators have been tabulated in Table 3.

\section{$10 \quad$ 2.3.2 MCDM technique}

11 In this research, the Technique for Order Preference by Similarity to Ideal Solution (TOPSIS) 12 has been used as the MCDM technique. This has been used in numerous research to rank the 13 CMIP models (e.g. Li et al 2019; Nashwan and Shahid 2020; Song et al. 2021; Kamruzzaman et 14 al. 2021). In this technique, the best alternative is determined based on the shortest distance to 15 ideal and longest distance to anti-ideal solutions. To this aim, a payoff matrix has been

16 generated. The performance criteria represent columns and CMIP6-GCMs form the rows of the 17 payoff matrix. To limit the payoff matrix values in a range between zero and one, the payoff 18 matrix has been normalized using sum normalization. Hence, the normalized values in each 19 column show the probability. The allocation of weights to each element of the normalized payoff 20 matrix has been employed using the entropy method. The entropy method measures the 21 uncertainty in the context of probability theory; smaller the entropy more the information 22 quantity. This method is an objective weighting method based on the equations as below:

$23 \quad E_{j}=-\left(\frac{1}{n}\right) \sum_{j=1}^{n} N_{i j} \log _{e}\left(N_{i j}\right)$,

$24 d_{j}=1-E_{j}$,

$25 w_{j}=\frac{d_{j}}{\sum_{j=1}^{J} d_{j}}$, 
1 where, $N$ represents the normalized payoff matrix and the index of $i j$ refers to the element in the

$2 i$ th row and $j$ th column. The number of performance evaluation metrics is $n$. Entropy, divergence

3 and weight of the jth metrics is shown by $E_{j}, d_{j}$ and $w_{j}$, respectively. Due to the logarithmic

4 transformation in Eq.1-1, it is necessary to avoid negative and zero values. This issue has been

5 solved via subtracting the values from one (e.g. tabulating 1-KGE instead of KGE in the payoff

6 matrix). To unify all ideal solution to zero value, the above modification has been applied to SU

7 metric. A List of modified metrics has been shown in Table 3. The distance from the ideal and

8 anti-ideal solutions $\left(D S^{+}\right.$and $\left.D S^{-}\right)$for each row have been calculated as below:

$9 \quad D S_{i}^{+}=\sqrt{\sum_{j=1}^{J}\left(V_{i j}-I_{j}\right)^{2}}$,

$10 D S_{i}^{-}=\sqrt{\sum_{j=1}^{J}\left(V_{i j}-A I_{j}\right)^{2}}$,

$11 \quad R C_{i}=\frac{D S_{i}^{-}}{D S_{i}^{-}+D S_{i}^{+}}$,

12 where the $V$ shows the weighted and normalized payoff matrix, $I_{j}$ is the ideal value for the jth

13 column, $A I_{j}$ represent the anti-ideal value for the jth column and $R C_{i}$ is the relative closeness for 14 each performance indicators.

\section{3. Results and Discussion}

16 In this research, climate of Sistan-and-Baluchestan Province has been assessed using two climate

17 variables of surface air temperature and precipitation. Low number of meteorological stations in

18 this province, led to use the CRU gridded data, which needs to be verified using in-situ data.

19 Therefore, after clarifying the accuracy of CRU data, they will be used to evaluate twenty-seven

20 CMIP6-GCMs' performance from historical runs over the selected area during 1979-2020. In the

21 evaluation process, eight metrics and TOPSIS MCDM method will be used and the three high-

22 ranked models will be determined. Then, behavior of twenty-seven CMIP5 GCMs simulations

23 under SSP5-8.5 and SSP3-7.0 scenarios for the three future decades (2021-2050) will be

24 investigated. Finally, the behavior of climatic variables over Sistand-and-Baluchestan Province

25 in future will be presented. The results have been presented as below. 


\section{3.1. CRU data}

\section{$2 \quad$ 3.1.1. Verification}

3 The bias values for surface air temperature and precipitation between in-situ data and CRU data

4 at the weather stations have been listed in Table 4. The cold bias values using CRU data are clear

5 for 12 stations, with the mean bias value of $-1.78 \mathrm{~K}$. The maximum cold bias value of around -5

$6 \mathrm{~K}$ occurred at Mirjaveh and Rask stations with a short data record, while this reduced to $0.17 \mathrm{~K}$

7 and $-0.09 \mathrm{~K}$ for Chabahar and Zabol stations with long-record data. In the precipitation term, the

8 CRU data produced about 0.19 wet bias over the area. These indicate that the CRU data had a

9 negligible error over the area and can be used for evaluation purpose.

\section{3.1.2. Horizontal distributions}

11 The averaged distribution of monthly surface air temperature (Figure 2a) and precipitation 12 (Figure 2b) obtained from CRU during 1979-2020 have been calculated. A cold and wet center 13 in the upper part of the area is evident. The latitudinal distributions of monthly surface air 14 temperature and precipitation for 12 months during 1979-2020 have been depicted in Figures 2b 15 and 2d. This Figure shows the warm season duration (from the middle of May to the end of July) 16 for the whole considered latitudes, while the cold season is only seen in the latitudes upper than $1727^{\circ} \mathrm{N}$. The considered area experienced the precipitation more than $10 \mathrm{~mm} / \mathrm{month}$ only at around 18 four months.

\section{3.2. CMIP6-GCMs}

20 Performance of twenty-seven CMIP6-GCMs has been evaluated using model outputs under 21 historical experiment and CRU data for the two considered climate variables in the period 197922 2020. The behavior of these variables for the three future decades will be investigated using 23 twenty-seven CMIP6-GCMs outputs under SSP5-8.5 and SSP3-7.0 scenarios with highlighting 24 the three high-ranked models determined in the evaluation process. The results have been 25 presented as below. 


\subsubsection{Evaluation of CMIP6-GCMs historical simulations}

a. Temperature

4 air temperature and precipitation time series during 1979-2020 from twenty-seven CMIP6-

GCMs historical runs and also CRU data (the last row). All CMIP6-GCMs have reached the increasing trend $(-0.002<\mathrm{a}<0.005)$ for temperature. The related increasing trend found in CRU data shows the slope of 0.004 and an intercept of $294.8 \mathrm{~K}\left(21.8^{\circ} \mathrm{C}\right)$. Distribution and probability of density of monthly temperature from the models and those from the CRU data have been visualized in Figure 3. Most of CMIP6-GCMs have simulated the lower median values of monthly temperature than the CRU data. The smallest density values are seen around the minimum values. All models and CRU data show negatively skew in temperature distribution.

For more detail, annual mean of surface air temperature anomalies has been also analyzed. Figure 4 indicates that in spite of increasing trend in all CMIP6-GCMs historical simulations, the distribution variability of surface air temperature was not the same and varied from $0.01 \mathrm{~K}$ to $0.06 \mathrm{~K}$, while that was $0.05 \mathrm{~K}$ for CRU data set. The UKESM1-0-LL, CanESM5-CanOE, ACCESS-CM2, CESM2-WACCM-FV2 and TaiESM1 models have simulated the most interdecadal variability of the surface air temperature and the MIROC6 and CNRM-CM6-1 and CAMS-CSM1-0 models produced the least variability. All CMIP6-GCMs, same as CRU data, have produced negative anomalies for the surface air temperature at the beginning of the studied period and reached the positive values at the end of that. Twenty-two CMIP6-GCMs produced slower increasing trend (slope $<0.05$ ) than CRU data set. The level plot of annual temperature averaged over the studied area from twenty-seven CMIP6-GCMs and CRU data have been presented in Figure 5. This figure shows the temporal change of surface air temperature during the evaluation period. The weak performance of MIROC6 and CNRM-CM6-1 models for the whole of the period is evident in this figure. The IPSL-CM6A-LR, KACE-1-0-G and MCM-UA1-0 models also performed poorly at the beginning of the studied period.

The discrepancy of horizontal distributions between surface air temperature from the twentyseven CMIP6-GCMs historical outputs and CRU data has been prepared in Figure 6. These 
1 horizontal distributions show the maximum cold bias of $-4 \mathrm{~K}$ and maximum warm bias of $10 \mathrm{~K}$.

2 Most of the models produced a dipole pattern, a warm region in the east and a cold region in the

3 west with various extensions. The largest warm bias has been achieved using MIROC6 model,

4 while IPSL-CM6A-LR and KACE-1-0-G models generated the largest cold bias.

5 For an easier comparison between twenty-seven CMIP6-GCMs outputs and CRU gridded 6 data, the Taylor diagram (Taylor et al. 2012) has been prepared. Figure 7a demonstrates that in 7 the historical simulations the FGOALS-g3, MPI-ESM1-2-LR, KACE-1-0-G and IITM-ESM 8 models have produced the smallest RMSE $(<1.6 \mathrm{~K})$ and STD 8 K for the monthly temperature 9 averaged over the Sistan-and-Baluchestan Province. All CMIP6-GCMs generated monthly 10 temperature in an acceptable consistency with CRU data (correlation coefficient > 0.95). It is 11 notable that the results from TaiESM1 and UKESM1-0-LL models could not be fitted in Taylor 12 diagram due to $\mathrm{RMSE}=2.39$ and $1.87, \mathrm{r}=0.97$ and 0.97 , and $\sigma=9.2$ and 8.34, respectively. To 13 cope this issue, the performance of twenty-seven CMIP6-GCMS has been ranked using eight 14 performance indicators in TOPSIS MCDM technique (Figure 7b). The three models with the 15 highest degree of accuracy in surface air temperature are CESM2-WACCM-FV2, MPI-ESM1-216 LR and IITM-ESM models, respectively. The two lowest values of performance have been 17 produced using MCM-UA-1-0 and MIROC6 models.

\section{b. Precipitation}

19 Table 5 indicates that the historical simulations of CMIP6-GCMs do not show a similar behavior 20 for precipitation. Similar to $\mathrm{CRU}$ data, fifteen models reached the decreasing trend for 21 precipitation, while the remaining twelve models showed the positive incline. The maximum 22 value of monthly precipitation simulated by the models varies from 48.250 to $259.77 \mathrm{~mm} / \mathrm{month}$, 23 while CRU data did not exceed $63.71 \mathrm{~mm} / \mathrm{month}$ over the area. The violin plots of monthly 24 precipitation simulated by the historical runs of CMIP6-GCMs and that from CRU data have 25 been plotted in Figure 8. All batches have been positively skewed. The density traces, simulated 26 by different CMIP6-GCMs, are not the same as those obtained from CRU, especially for values 27 less than $10 \mathrm{~mm} / \mathrm{month}$. Figure 8 also demonstrates the various extreme values of monthly 28 precipitation for the selected area. The MIROC6 model generated the largest error. To evaluate 29 the simulated trends, time series of the regional annual monthly precipitation from twenty-seven 12 
1 CMIP6-GCMs and CRU data have been depicted in Figure 9. Historical simulations of the models produced annual variability of $1.91 \mathrm{~mm}$ (in the MPI-ESM1-2-LR model) to $7.52 \mathrm{~mm}$ (in

3 the MIROC-ES2L model), while CRU data showed $3.05 \mathrm{~mm}$ variability. The 4 decreasing/increasing trends of annual precipitation are evident in this figure. The level types of 5 annual precipitation from CMIP6-GCMs and CRU data have been depicted in Figure 10.

6 Compared with results obtained for surface air temperature, the CMIP6-GCMs produced lower 7 satisfactory in precipitation. For more details, the difference between the horizontal distribution 8 of monthly precipitation between historical runs of CMIP6-GCMs and the CRU dataset has been 9 calculated. Figure 11 shows that dry and wet bias varies from -6 to $20 \mathrm{~mm} / \mathrm{month}$. ACCESS10 CM2, CanESM5-CanOE, KACE-1-0-G, MPI-ESM1-2-LR, TaiESM1 and UKESM1-0-LL 11 models simulated dry bias ( $<6 \mathrm{~mm} /$ month) over the whole of the terrain, while BCC-CSM2-MR, 12 CESM2, CESM2-WACCM-FV2, CMCC-CM2-SR5, three CNRM*, FGOALS*, GFDL-ESM4, 13 MCM-UA-1-0, MIROC*, MRI-ESM2-0 and NorESM2-MM models produced wet bias (up to 20 $14 \mathrm{~mm}$ per month) over the selected area. The other seven models generated a combined pattern of 15 positive and negative bias for precipitation.

The Taylor diagram depicted in Figure 12a analyzes the performances statistically. It 17 illustrates that the consistency between monthly precipitation from CRU and historical runs of 18 CMIP6-GCMs is lower than 0.5. The historical simulations of MPI-ESM1-2-LR, ACCESS-CM2 and IITM-ESM models have produced monthly precipitation with the smallest RMSE values (

$2013 \mathrm{~mm}$ per month). Results of the TaiESM1 and UKESM1-0-LL models could not be included in 21 this diagram, due to their $\sigma=9.64$ and 7.67, RMSE $=14.9$ and 13.07 and $r=0.95$ and 0.20

22 values, respectively. TOPSIS MCDM technique with eight metrics was utilized to achieve a 23 comprehensive understanding of the performance of the models and rank them. Figure 12b 24 shows that the MPI-ESM1-2-LR, UKESM1-0-LL (however, with the wrong trend for annual 25 values) and ACCESS-CM2 models performed the best, while the MIROC6 and MCM-UA-1-0 26 models did the worst, respectively. The rank of the CMIP6-GCMs' performance in simulating 27 surface air temperature and precipitation and their final rank have been tabulated in Table 6. The 28 highest rank values belong to MPI-ESM1-2-LR, UKESM1-0-LL and ACCESS-CM2 models. 
3.2.2. SSP5-8.5 and SSP3-7.0 scenarios

2 The results obtained using SSP5-8.5 and SSP3-7.0 runs of the twenty-seven CMIP6-GCMs for

3 the two parameters of surface air temperature and precipitation during 2021-2050 have been

4 presented as below.

5 a. Temperature

6 Figure 13a and 13b shows the violin plot of simulated monthly surface air temperature. Similar

7 to those obtained for the historical runs, a negative skewness with the lowest probability of the

8 minimum values is evident for most models. A few models show the symmetric distribution.

9 Simulated minimum and maximum values from the three high-ranked models (based on the

10 results from the evaluation of the historical experiments) have been distinguished in Figure 13.

11 These models predicted 2.5-3.4 (2.2-3.1) degrees increase in the maximum of surface

12 temperature under SSP5-8.5 (SSP3-7.0) scenario, comparing with the CRU data in 1979-2020.

13 The predicted minimum values also vary from -1.3 to 1.8 (from -0.1 to 1.3) under SSP5-8.5

14 (SSP3-7.0) scenario. MIROC6 and MCM-UA-1-0 models predicted highest maximum and the

15 lowest minimum values of surface air temperature for the three next decades.

16 Trend of annual mean of surface air temperature under SSP5-8.5 and SSP3-7.0 scenarios 17 have been calculated and plotted in Figure 14a and 14b, respectively. This figure shows that all 18 CMIP6-GCMs predicted an increasing trend for temperature in the studied province. The 19 positive values of the simulated slopes vary from 0.03 to 0.08 . In addition, the predicted $\sigma$ values 20 have been ranged in 0.48-0.93 (0.52-0.82) degrees in SSP5-8.5 (SSP3-7.0) scenario. The Slope 21 and intercept of linear lines fitted to the temperature from both scenarios have been listed in 22 Table 7. This table indicates that under both scenarios, the three high-ranked CMIP6-GCMs 23 show the increasing trend for surface air temperature. Averaged horizontal distributions of 24 simulated monthly surface air temperature have been shown in Figure 15 (16) for SSP5-8.5 25 (SSP3-7.0) scenario. Intrusion of warm air from the southwest of the province to the southeast of 26 that has been appeared in the most outputs with various extensions and values. For the lesser 27 latitudes, performance of MPI-ESM1-2-LR and UKESM1-0-LL models and relatively outputs 28 from the ACCESS-CM2 model are similar. However, for the higher latitudes, a little difference 29 in distribution is seen. 


\section{b. Precipitation}

2 Variability of the averaged value of monthly precipitation produced by twenty-seven CMIP6-

3 GCMs under both scenarios during 2021-2050 has been shown in Figures 17a and 17b. Decrease

4 of maximum values of monthly precipitation from the three highest-ranked models under SSP5-

58.5 scenario is evident (figure 17a). Figure $17 \mathrm{~b}$ shows that the maximum values of monthly

6 precipitation of the mentioned models under SSP3-7.0 scenario will increase. However, the

7 twenty-seven CMIP6-GCMs have not shown similar trends for the annual precipitation under the

8 both scenarios (Figures 18a and b), but the three highest-ranked models predicted a decreasing

9 trend with $0.001<$ slope $<4.66$ and $2.06<\sigma<4$.66. Detailed characteristics of the linear fitted lines

10 can be found in Table 7.

11 Figure 19 shows that under SSP5-8.5 scenario, the ACCESS-CM2 model predicted 12 precipitation less than $12 \mathrm{~mm} /$ month over the southwest of the area and less than $8 \mathrm{~mm} / \mathrm{month}$ 13 for the other parts, while the MPI-ESM1-2-LR and UKESM1-0-LL models generated 14 precipitation less than $8 \mathrm{~mm} /$ month. Under the SSP3-7.0 scenario, ACCESS-CM2 model 15 simulated around $8 \mathrm{~mm} / \mathrm{month}$ for the whole of the terrain and the MPI-ESM1-2-LR and 16 UKESM1-0-LL models predicted this maximum value only for a limited area (Figure 20).

17 Finally, the decrease of the precipitation amount is evident for the three future decades.

\section{4. Summary and conclusions}

19 Here, long-term variations of surface air temperature and precipitation for the Sistan-and20 Baluchestan Province were analyzed to reach their probable behavior in the three next decades.

21 To this aim, observational data measured at thirteen weather stations, CRU gridded data, and 22 outputs of twenty-seven CMIP6-GCMs (under historical runs, SSP5-8.5 and SSP3-7.0 scenarios)

23 were used. The climatic analysis of the two climatic factors was conducted in three steps.

At the first step, CRU gridded data were compared with the in-situ data for the retrospective period 1979-2020, based on the recording duration in each weather station. The

26 calculated bias values showed that the CRU data had sufficient accuracy to be used for the 27 evaluation process. 
In the second step, performance of the twenty-seven CMIP6-GCMs was evaluated comparing with the CRU data during 1979-2020. In the evaluation process, time series of annual values of the anomalies, long-term trends, horizontal distributions, probability density and visualization of the annual values all from the CRU data and CMIP6-GCMs were prepared and compared. The findings for surface air temperature and precipitation have been listed as below:

(a) The results demonstrated the increasing trend for temperature both in the historical run of the twenty-seven CMIP6-GCMs and CRU data, however with different variability and slope values. The discrepancy of horizontal distributions between CRU data and most of CMIP6-GCMs showed a 10-degree warm bias (-4-degree cold bias) in the eastern-half (central west). Since the statistical metrics of RMSE, $r$ and $\boldsymbol{\sigma}$ values for two models could not be fitted in the Taylor diagram, the effective and widely applied multiobjective decision method of TOPSIS (from the MCDM technique) was used to comprehensively evaluate the CMIP6-GCMs performance. Therefore, eight performance indicators of BD, R4MS4E, KGE, MAE, NSE, RMSE, SS and SU were applied. The findings indicated that the three models of CESM2-WACCM-FV2, MPI-ESM1-2-LR and IITM-ESM surpassed the others in simulating temperature, while the models of MIROC6 and MCM-UA-1-0 generated the worst performance.

(b) Twelve models of the selected CMIP6-GCMs failed in producing decreasing trends of precipitation, while the CRU data showed a decreasing trend. Moreover, most of CMIP6-GCMs overestimated the horizontal distribution of precipitation over the area. Based on the TOPSIS-MCDM technique the three models of MPI-ESM1-2-LR, UKESM1-0-LL and ACCESS-CM2 outperformed the others in simulating precipitation over the area, while the MIROC-ES2L and MCM-UA-1-0 models exhibited the weakest performance.

The three models of MPI-ESM1-2-LR, UKESM1-0-LL and ACCESS-CM2 achieved the highest rank for the both climate variables of surface air temperature and precipitation. It is noticeable that these three models had the resolution of $250 \mathrm{~km}$. It is noteworthy that Zamani1and Berndtsson (2019) found that the MIROC-ESM (BCC-CSM1.1) from CMIP5 had the maximum relative closeness to the ideal solution for the Zard River basin 
(Bakhtegan basin) in the west of Iran during 1976 to 2005. Katiraie-Boroujerdy et al. (2019) introduced the CCSM4 (from CMIP5) with the highest correlation coefficients and lowest RMSE for the mean annual precipitation over the whole of Iran. Miri et al. (2021) showed the historical temperatures estimated by all CMIP5 models were highly correlated with the observed temperatures all over Iran from 1987 to 2014. In their research, the highest accuracy was found in the mountainous areas of the western part during, while the accuracy decreased in the coastal areas of southern and northern Iran due to the complex topographical structure of the other effective local features that had not been incorporated in the models. This finding clearly proves the importance of the study in the coastal and southern parts of Iran.

In the third step, the outputs of the CMIP6-GCMs, under SSP5-8.5 and SSP3-7.0 scenarios were investigated for the next three decades (2021-2050). With respect to the three high-ranked models from the evaluation process (in the second step), both scenarios predicted that the probability of occurrence of the lowest temperature, recorded during 1979-2020, would decrease. In addition, the maximum temperature will increase about 2.5-3.4 (2.2-3.1) degree under SSP58.5 (SSP3-7.0) scenario, compared with the values in the historical experiment and CRU data. Both scenarios, predicted an increasing trend for the annual temperature. In spite of the different behavior of CMIP6-GCMs in predicting precipitation trends for 2021-2050, the three highranked models showed decreasing trends. Meanwhile, the MPI-ESM1-2-LR and UKESM1-0-LL models showed a sharper decline. The results of the three highest-ranked models under the two scenarios, as increasing (decreasing) trend of temperature (precipitation), were similar.

Conclusively, this research comprehensively investigated the performance of twenty-seven CMIP6-GCMs and showed that the climate change in the shape of increase of surface air temperature and decrease of precipitation amount over the Sistan-and-Baluchestan Province would be expected for the next three decades (2021-2050). It is noteworthy that the results obtained during this research only reflect the changes predicted in the models in global scale, while the role of environment in regional and local scale and more importantly the impact of policies adopted, which are able to intensify these findings, also should be also considered. This means that the selected area is prone to experience a high degree of climate change (more severe 17 
1 than before) and needs precise policymaking. Therefore, the provided information from the

2 present work can be applied in governmental policies for decision making in economic-social

3 structures, ecology protection, agricultural production and public health, especially in risk

4 management for food security and water resource. Therefore, more exact policies and precise

5 planning are needed for such a strategic area and ignoring this issue for this province with a

6 significant nomadic population and the only international port of Iran will cause irreparable

7 damage leading to human migration.

8 Acknowledgment

9 The author would like to acknowledge the World Climate Research Programme's Working 10 Group on Coupled Modelling, which is responsible for CMIP, and to thank the climate 11 modelling groups for producing and making available their model outputs

12 (https://esgfnode.llnl.gov/projects/esgf-llnl/). In addition, the CRU data have been downloaded

13 from https://crudata.uea.ac.uk/cru/data/hrg/.

\section{5. Statements and Declarations}

15 Funding: 'Not applicable'

16 Conflicts of interest/Competing interests: 'Not applicable'

17 Ethics approval: The author approves that she does the results presented in this manuscript.

18 Consent to participate: The author prepared this manuscript, agreed with the content, and gave

19 explicit consent to submit that.

20 Consent for publication: The author consents to publish her results in TAAC journal.

21 Availability of data and material/ Data availability: The data used in this research includes

22 free data from CRU and CMIP6-GCMs. The related links have been included in the

23 acknowledgement.

24 Code availability: 'Not applicable'

25 Authors' contributions: The author contributed to the whole of this research in conception and 26 design.

\section{Reference}

29 Ahmed, A., Suleiman, M., Abubakar, M.J. \& Saleh, A., (2021). Impacts of climate change on agriculture in Senegal: A systematic review. Journal of Sustainability, Environment and Peace, 4(1), 30-38. 
Anil, S., Manikanta, V., \& Pallakury, A. R. (2021). Unravelling the influence of subjectivity on ranking of CMIP6 based climate models: A case study. International Journal of Climatology.

Baker, N. C., \& Huang, H.P. (2014). A comparative study of precipitation and evaporation between CMIP3 and CMIP5 climate model ensembles in semiarid regions. Journal of Climate, 27(10), 3731-3749.

Barry, A. A., Caesar, J., Klein Tank, A. M. G., Aguilar, E., McSweeney, C., Cyrille, A. M., ... \& Laogbessi, E. T. (2018). West Africa climate extremes and climate change indices. International Journal of Climatology, 38, e921-e938.

Beine, M., Noy, I. \& Parsons, C., (2021). Climate change, migration and voice. Climatic Change, 167(1), 1-27.

Cardoso Pereira, S., Marta Almeida, M., Carvalho, A. C., \& Rocha, A. (2020). Extreme precipitation events under climate change in the Iberian Peninsula. International Journal of Climatology, 40(2), 1255-1278.

Christidis, N., Mitchell, D. \& Stott, P.A., (2019). Anthropogenic climate change and heat effects on health. International Journal of Climatology, 39(12), 4751-4768.

Collados-Lara, A. J., Pardo-Igúzquiza, E., Pulido-Velazquez, D., \& Jiménez-Sánchez, J. (2018). Precipitation fields in an alpine Mediterranean catchment: Inversion of precipitation gradient with elevation or undercatch of snowfall?. International Journal of Climatology, 38(9), 3565-3578.

Dehghani, M., Saghafian, B., Nasiri Saleh, F., Farokhnia, A., \& Noori, R. (2014). Uncertainty analysis of streamflow drought forecast using artificial neural networks and Monte-Carlo simulation. International Journal of Climatology, 34(4), 1169-1180.

Donnelly, C., Greuell, W., Andersson, J., Gerten, D., Pisacane, G., Roudier, P. \& Ludwig, F. (2017). Impacts of climate change on European hydrology at 1.5, 2 and 3_ mean global warming above preindustrial level. Climatic Change, 143(3-4), 13-26. 
Doyle, M. E. (2020). Observed and simulated changes in precipitation seasonality in Argentina. International Journal of Climatology, 40(3), 1716-1737.

Duan, K., Mei, Y., (2014). A comparison study of three statistical downscaling methods and their model-averaging ensemble for precipitation downscaling in China. Theor. Appl. Climatol., 116(3-4), 707-719.

Eyring, V., Bony, S., Meehl, G. A., Senior, C. A., Stevens, B., Stouffer, R. J., \& Taylor, K. E. (2016). Overview of the Coupled Model Intercomparison Project Phase 6 (CMIP6) experimental design and organization. Geoscientific Model Development, 9(5), 19371958.

Gao, Y., Xiao, L., Chen, D., Xu, J. \& Zhang, H. (2018). Comparison between past and future extreme precipitations simulated by global and regional climate models over the Tibetan Plateau. International Journal of Climatology, 38(3), 1285-1297.

Ghalami, V., Saghafian, B., \& Raziei, T. (2021). Trend analysis of evapotranspiration over Iran based on NEX-GDDP high-resolution dataset. International Journal of Climatology, 41, E2073-E2096.

Gupta, H.V., Kling, H., Yilmaz, K.K. and Martinez, G.F. (2009) Decomposition of the mean squared error and NSE performance criteria: implications for improving hydrological modelling. Journal of Hydrology, 377, 80-91.

Heinze, C., Eyring, V., Friedlingstein, P., Jones, C., Balkanski, Y., Collins, W., ... \& Vancoppenolle, M. (2019). ESD Reviews: Climate feedbacks in the Earth system and prospects for their evaluation. Earth System Dynamics, 10(3), 379-452.

Homsi, R., Shiru, M. S., Shahid, S., Ismail, T., Harun, S. B., Al-Ansari, N., ... \& Yaseen, Z. M. (2020). Precipitation projection using a CMIP5 GCM ensemble model: a regional investigation of Syria. Engineering Applications of Computational Fluid Mechanics, 14(1), 90-106. 
Hong, J., Javan, K., Shin, Y., \& Park, J. S. (2021). Future Projections and Uncertainty Assessment of Precipitation Extremes in Iran from the CMIP6 Ensemble. Atmosphere, 12(8), 1052.

Huang, W., Ge, Q., Wang, H., \& Dai, J. (2019). Effects of multiple climate change factors on the spring phenology of herbaceous plants in Inner Mongolia, China: Evidence from ground observation and controlled experiments. International Journal of Climatology, 39(13), 5140-5153.

Jiang, D., Tian, Z., Lang, X., (2016). Reliability of climate models for China through the IPCC third to fifth assessment reports. International Journal of Climatology, 36(3), 1114-1133.

Kaczan, D. J., \& Orgill-Meyer, J. (2020). The impact of climate change on migration: a synthesis of recent empirical insights. Climatic Change, 158(3), 281-300.

Kamruzzaman, M., Shahid, S., Roy, D. K., Islam, A. T., Hwang, S., Cho, J., ... \& Akter, F. Assessment of CMIP6 global climate models in reconstructing rainfall climatology of Bangladesh. International Journal of Climatology.

Katiraie-Boroujerdy, P. S., Akbari Asanjan, A., Chavoshian, A., Hsu, K. L., \& Sorooshian, S. (2019). Assessment of seven CMIP5 model precipitation extremes over Iran based on a satellite-based climate data set. International Journal of Climatology, 39(8), 3505-3522.

Keellings, D. (2016). Evaluation of downscaled CMIP5 model skill in simulating daily maximum temperature over the southeastern United States. International Journal of Climatology, 36(12), 4172-4180.

Khadka, D., Babel, M. S., Abatan, A. A., \& Collins, M. (2021). An evaluation of CMIP5 and CMIP6 climate models in simulating summer rainfall in the Southeast Asian monsoon domain. International Journal of Climatology.

Koutroulis, A. G., Grillakis, M. G., Tsanis, I. K., \& Papadimitriou, L. (2016). Evaluation of precipitation and temperature simulation performance of the CMIP3 and CMIP5 historical experiments. Climate Dynamics, 47(5), 1881-1898. 
Li, J., Liu, Z., Yao, Z., \& Wang, R. (2019). Comprehensive assessment of Coupled Model Intercomparison Project Phase 5 global climate models using observed temperature and precipitation over mainland Southeast Asia. International Journal of

5 Li, M., Wu, P. \& Ma, Z., (2020). A comprehensive evaluation of soil moisture and soil

11 Lun, Y., Liu, L., Cheng, L., Li, X., Li, H., \& Xu, Z. (2021). Assessment of GCMs simulation temperature from third-generation atmospheric and land reanalysis data sets. International Journal of Climatology, 40(13), 5744-5766.

Liu, Z., Liu, Y., \& Li, Y. (2019). Extended warm temperate zone and opportunities for cropping system change in the Loess Plateau of China. International Journal of Climatology, 39(2), 658-669. performance for precipitation and temperature from CMIP5 to CMIP6 over the Tibetan Plateau. International Journal of Climatology, 41(7), 3994-4018.

Luo, N., Guo, Y., Chou, J., \& Gao, Z. (2021). Added value of CMIP6 models over CMIP5 models in simulating the climatological precipitation extremes in China. International Journal of Climatology.

Miri, M., Samakosh, J. M., Raziei, T., Jalilian, A., \& Mahmodi, M. (2021). Spatial and temporal variability of temperature in Iran for the twenty-first century foreseen by the CMIP5 GCM models. Pure and Applied Geophysics, 178(1), 169-184.

Nash, J.E. and Sutcliffe, J.V. (1970) River flow forecasting through conceptual models part Ia discussion of principles. Journal of Hydrology, 10(3), 282-290.

Nashwan, M.S. and Shahid, S. (2020) A novel framework for selecting general circulation models based on the spatial patterns of climate. International Journal of Climatology, $40(10), 4422-4443$. 
Ngoma, H., Wen, W., Ayugi, B., Babaousmail, H., Karim, R., \& Ongoma, V. (2021). Evaluation of precipitation simulations in CMIP6 models over Uganda. International Journal of Climatology.

O’Neill, B.C., Kriegler, E., Riahi, K., Ebi, K. L., Hallegatte, S., Carter, T. R., ... \& van Vuuren, D. P. (2014). A new scenario framework for climate change research: the concept of shared socioeconomic pathways. Climatic change, 122(3), 387-400.

Pegahfar, N. (2021). Climatic analysis of tropopause during the northwestern Indian Ocean tropical cyclones. Dynamics of Atmospheres and Oceans, 93, 101195.

Podineh, O., Delbari, M., Haghighatjou, P., \& Amiri, M. (2015). Spatial analysis of Precipitation with Elevation and Distance to Sea (Case Study: Sistan-and-Baluchestan Province). Physical Geography Research Quarterly, 47(4), 607-636.

Pörtner, H. O., Roberts, D., Masson-Delmotte, V., Zhai, P., Tignor, M., Poloczanska, E., ... \& Petzold, J. (2019). IPCC Special Report on the Ocean and Cryosphere in a Changing Climate: IPCC Intergovernmental Panel on Climate Change. Geneva, Switzerland, 1(3).

Quispe-Ccalluari, C., Tam, J., Demarcq, H., Chamorro, A., Espinoza-Morriberón, D., Romero, C., ... \& Oliveros-Ramos, R. (2018). An index of coastal thermal effects of El Niño Southern Oscillation on the Peruvian Upwelling Ecosystem. International Journal of Climatology, 38(7), 3191-3201.

Raziei, T., Daneshkar Arasteh, P., Akhtari, R. \& Saghafian, B., (2007). Investigation of meteorological droughts in the Sistan-and-Baluchestan province, Using the standardized precipitation index and Markov chain model. Iran-Water Resources Research, 3(1), 2535.

Saligeh, M., bareimanei, F., \& esmaeilnegad, M. (2008). Climatical Regionalization on Sistan \& Baluchestan Province. Geography And Development Iranian Journal, 6(12), 101-106. 
Samantaray, A. K., Ramadas, M., \& Panda, R. K. (2021). Assessment of impacts of potential climate change on meteorological drought characteristics at regional scales. International Journal of Climatology, 41, E319-E341.

Sharafati, A., Nabaei, S., \& Shahid, S. (2020). Spatial assessment of meteorological drought features over different climate regions in Iran. International Journal of Climatology, 40(3), 1864-1884.

Song, Y. H., Shahid, S., \& Chung, E. S. (2021). Differences in multi-model ensembles of CMIP5 and CMIP6 projections for future droughts in South Korea. International Journal of Climatology.

Taylor, K.E., Stouffer, R.J. \& Meehl, G.A., 2012. An overview of CMIP5 and the experiment design. Bulletin of the American meteorological Society, 93(4), 485-498.

Weedon, G.P., Balsamo, G., Bellouin, N., Gomes, S., Best, M.J. \& Viterbo, P., (2014). The WFDEI meteorological forcing data set: WATCH Forcing Data methodology applied to ERA-Interim reanalysis data. Water Resources Research, 50(9), 7505-7514.

Wen, S., Wang, Y., Su, B., Gao, C., Chen, X., Jiang, T., ... \& Zhai, J. (2019). Estimation of economic losses from tropical cyclones in China at $1.5^{\circ} \mathrm{C}$ and $2.0^{\circ} \mathrm{C}$ warming using the regional climate model COSMO-CLM. International Journal of Climatology, 39(2), 724737.

Xin, X., Wu, T., Zhang, J., Yao, J., \& Fang, Y. (2020). Comparison of CMIP6 and CMIP5 simulations of precipitation in China and the East Asian summer monsoon. International Journal of Climatology, 40(15), 6423-6440.

Xu, K., Yang, D., Yang, H., Li, Z., Qin Y., \& Shen, Y. (2015). Spatio-temporal variation of drought in China during 1961-2012: a climatic perspective. J Hydrol (Amst), 526, 253264. 
1 Zamani Y, Hasemi Monfared SA, amidianpour M, Azhdari moghaddam M (2019). The Changes in Sectors Demanding Water Resources on the Basis of Climate Change and Uncertainty. Int J Clim Change: Impacts \& Responses, 11(4).

4 Zamani, R. \& Berndtsson, R. (2019). Evaluation of CMIP5 models for west and southwest Iran 5 using TOPSIS-based method. Theoretical and Applied Climatology, 137(1-2), 533-543.

6 Zamani, Y., Monfared, S. A. H., \& Hamidianpour, M. (2020). A comparison of CMIP6 and 7 CMIP5 projections for precipitation to observational data: the case of Northeastern Iran. Theoretical and Applied Climatology, 142(3), 1613-1623.

9 Zare Abianeh, H., Sabziparvar, A., Marofi, S., Ghiyami, F., Mirmasoud, S., \& Kazemi, A. (2015). Analyzing and Monitoring the Meteorological Droughts in the Region of Sistanand-Baluchestan. Journal of Environmental Science and Technology, 17(1), 49-61.

12 Zarrin, A., \& Dadashi-Roudbari, A. (2021a). Projection of future extreme precipitation in Iran based on CMIP6 multi-model ensemble. Theoretical and Applied Climatology, 144(1), 643-660.

15 Zarrin, A., Dadashi Roudbari, A. (2020). Projection the Long-Term Outlook Iran Future 16 Temperature Based on the Output of The coupled model intercomparison project phase 6 17 (CMIP6). Journal of the Earth and Space Physics, 46(3), 583-602.

18 Zarrin, A., Dasdashi-Rodbari, A. (2021b). Projected consecutive dry and wet days in Iran based on CMIP6 bias-corrected multi-model ensemble. Journal of the Earth and Space Physics, 47(3), 561-578.

21 Zhao, Z., Luo, Y. \& Huang, J. (2020). Will global warming continue in the next 20 years? Climate Change Research, 5(16), 652-656. 


\section{Figures}
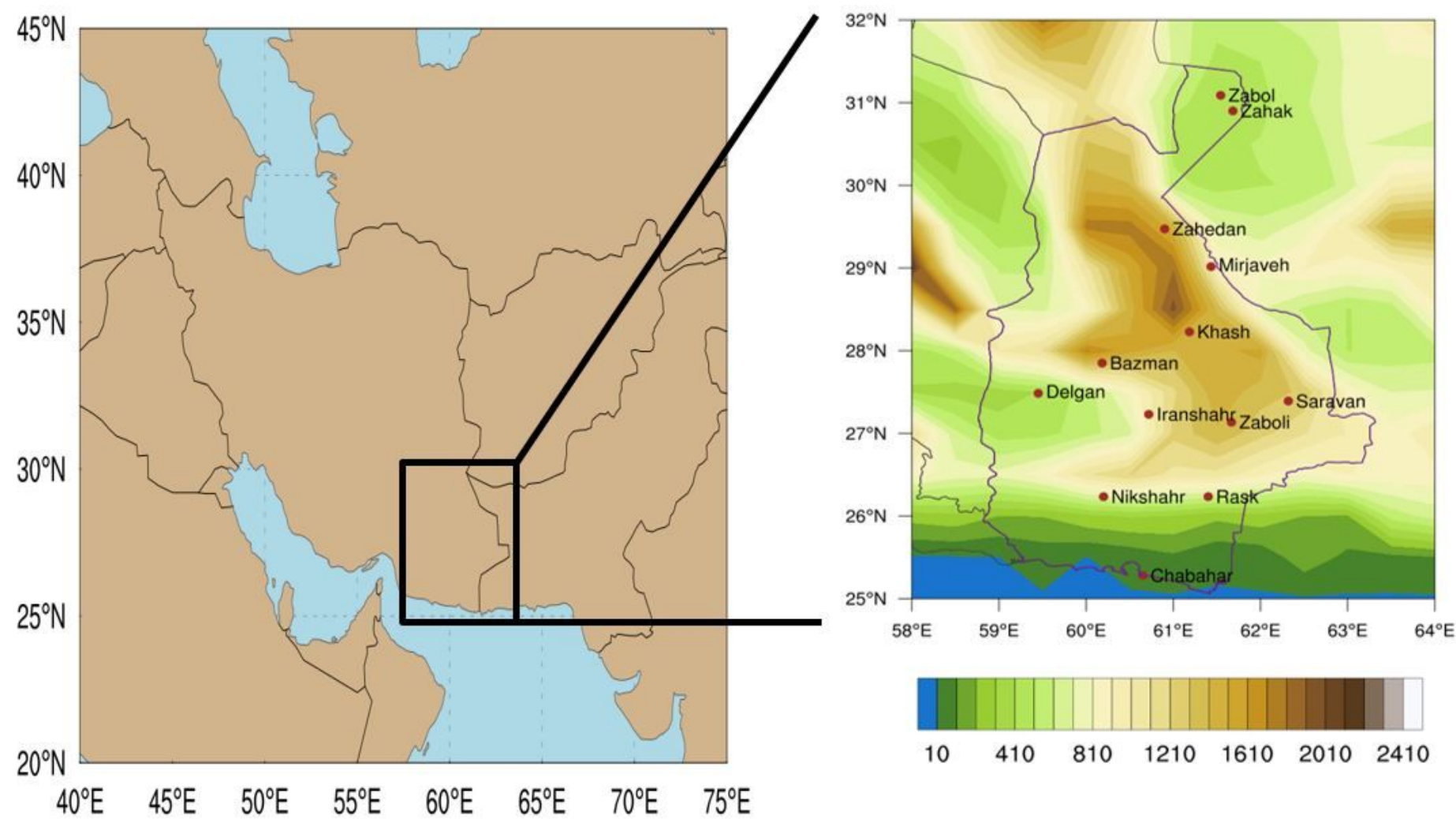

Figure 1

The map of Iran (left) and Sistan-and-Baluchestan Province with elevation from the sea (right). The stations have been indicated in brown dots. 
(a)
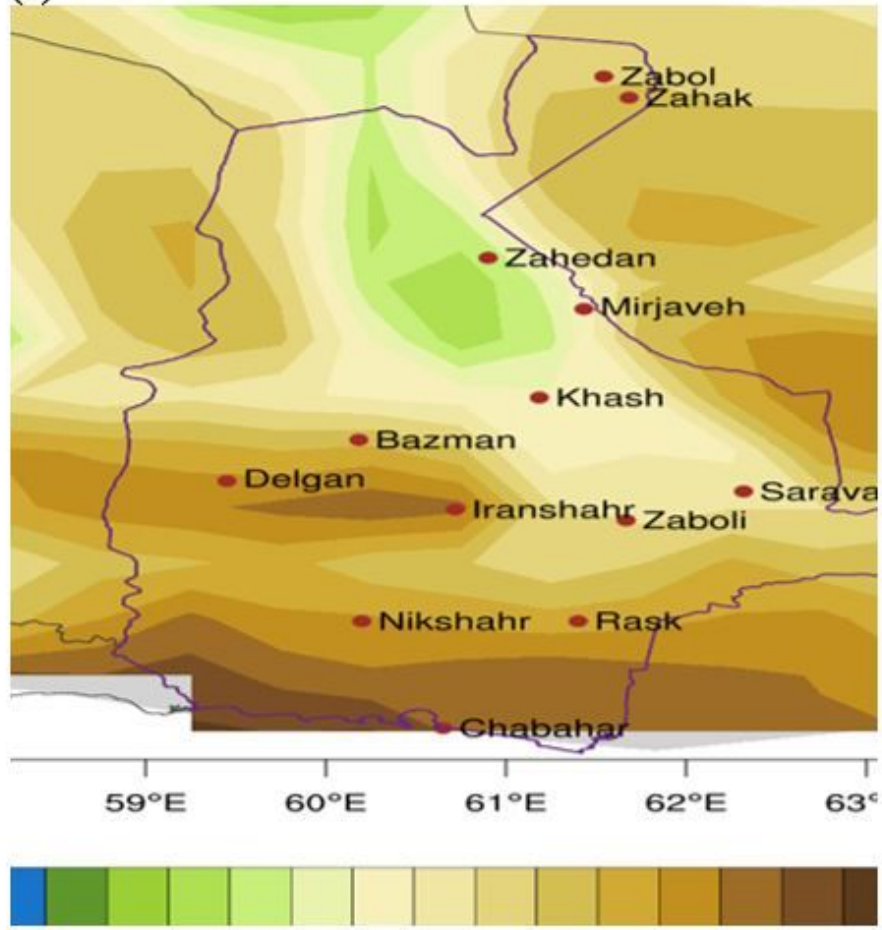

(c)
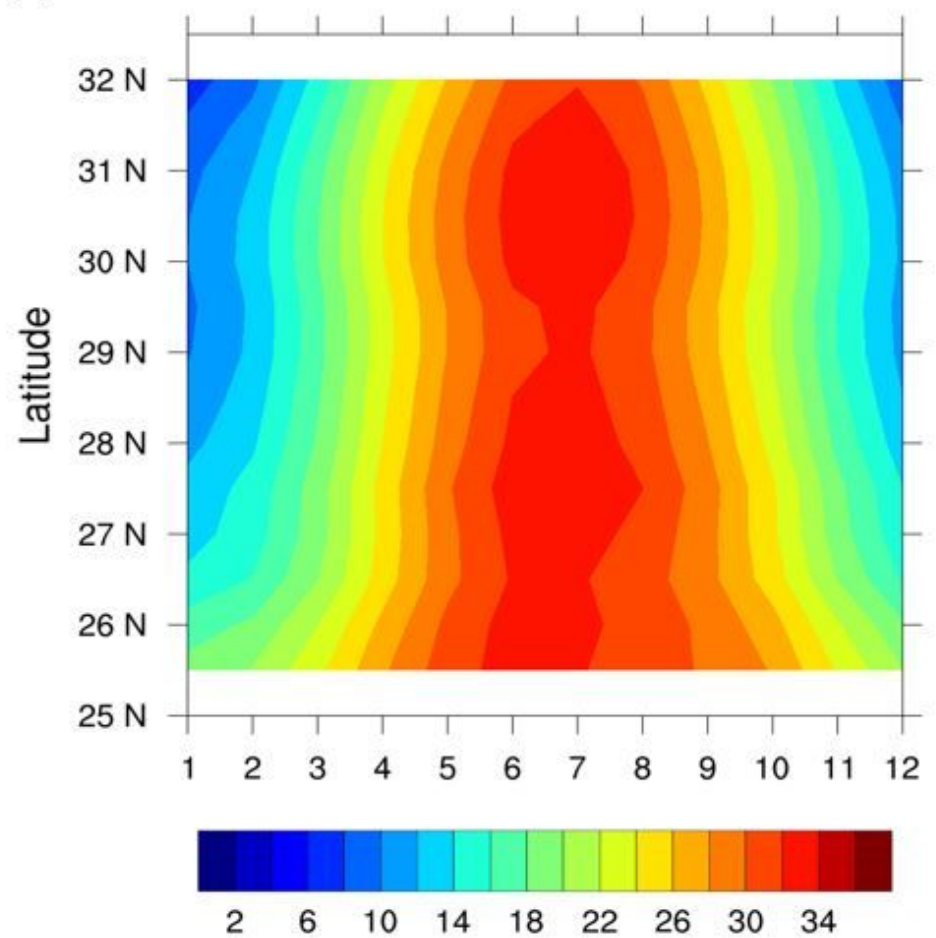

(b)

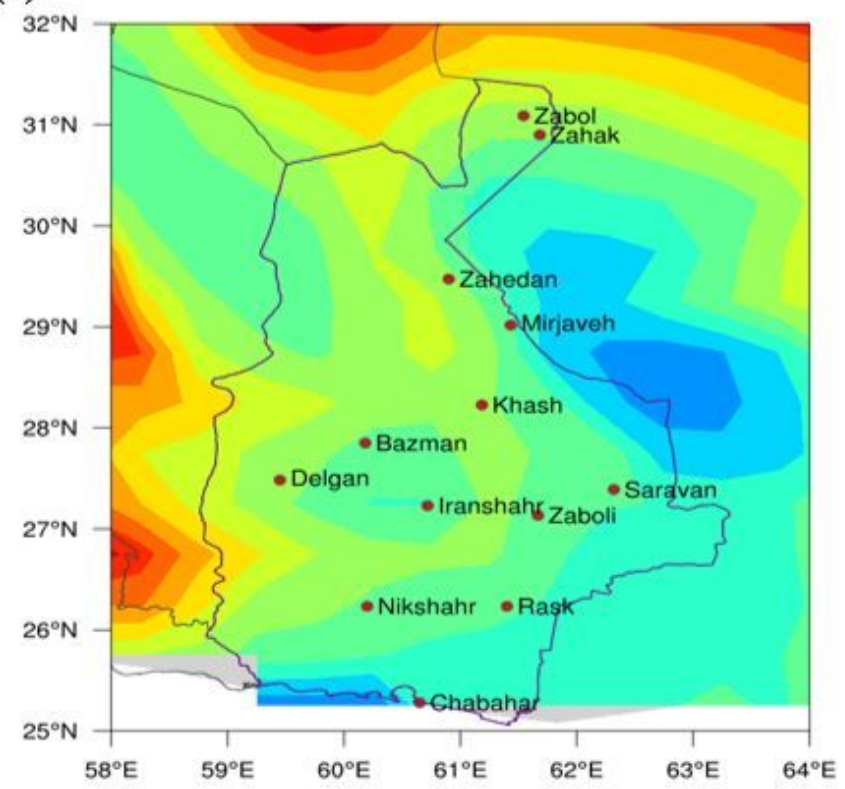

(d)

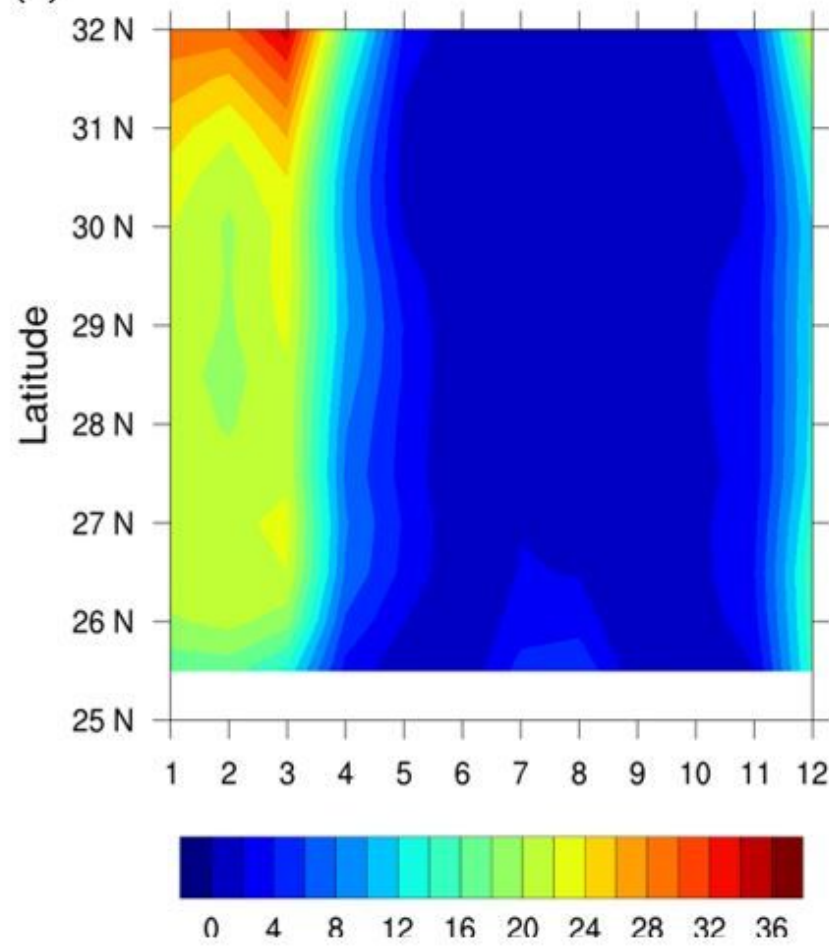

Figure 2

Latitude/longitude distribution of the averaged surface air temperature $(\mathrm{K})$ in (a) and precipitation (mm/month) in (b) during 1979-2020 from CRU data. The Latitudinal distribution of monthly averaged value of surface air temperature and precipitation for 12 months during 1979-2020 using CRU data have been depriced in (c) and (d). 


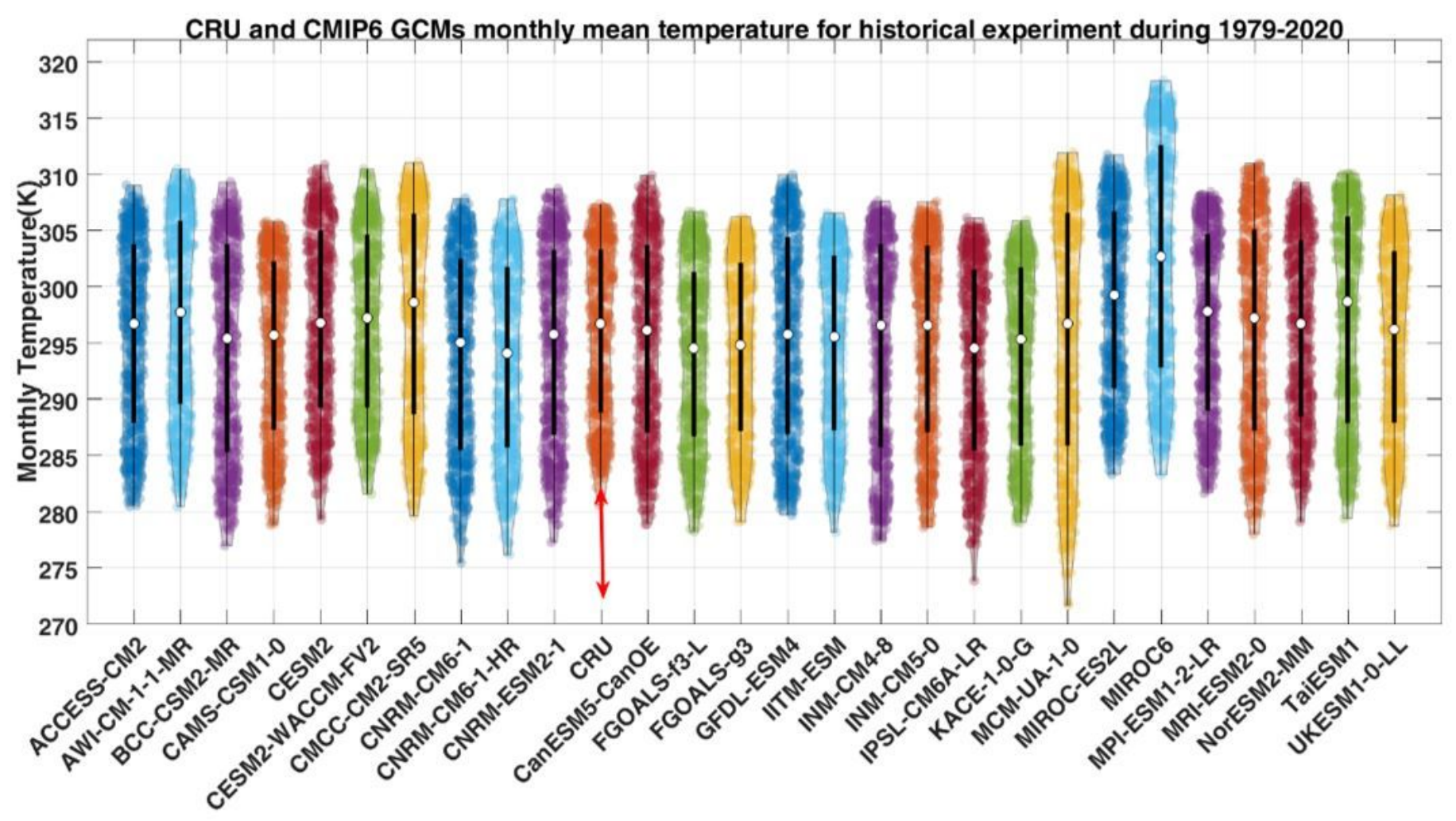

Figure 3

Violin plot of monthly surface air temperature (K) from the historical experiment of CMIP6-GCMs during 1979-2020 and from CRU data set. Since the horizontal axis is arranged alphabetically, results of CRU data have been highlighted with a red arrow. The median values have been depicted in white circles and the thick black lines show the limit of the first and third quartiles. 

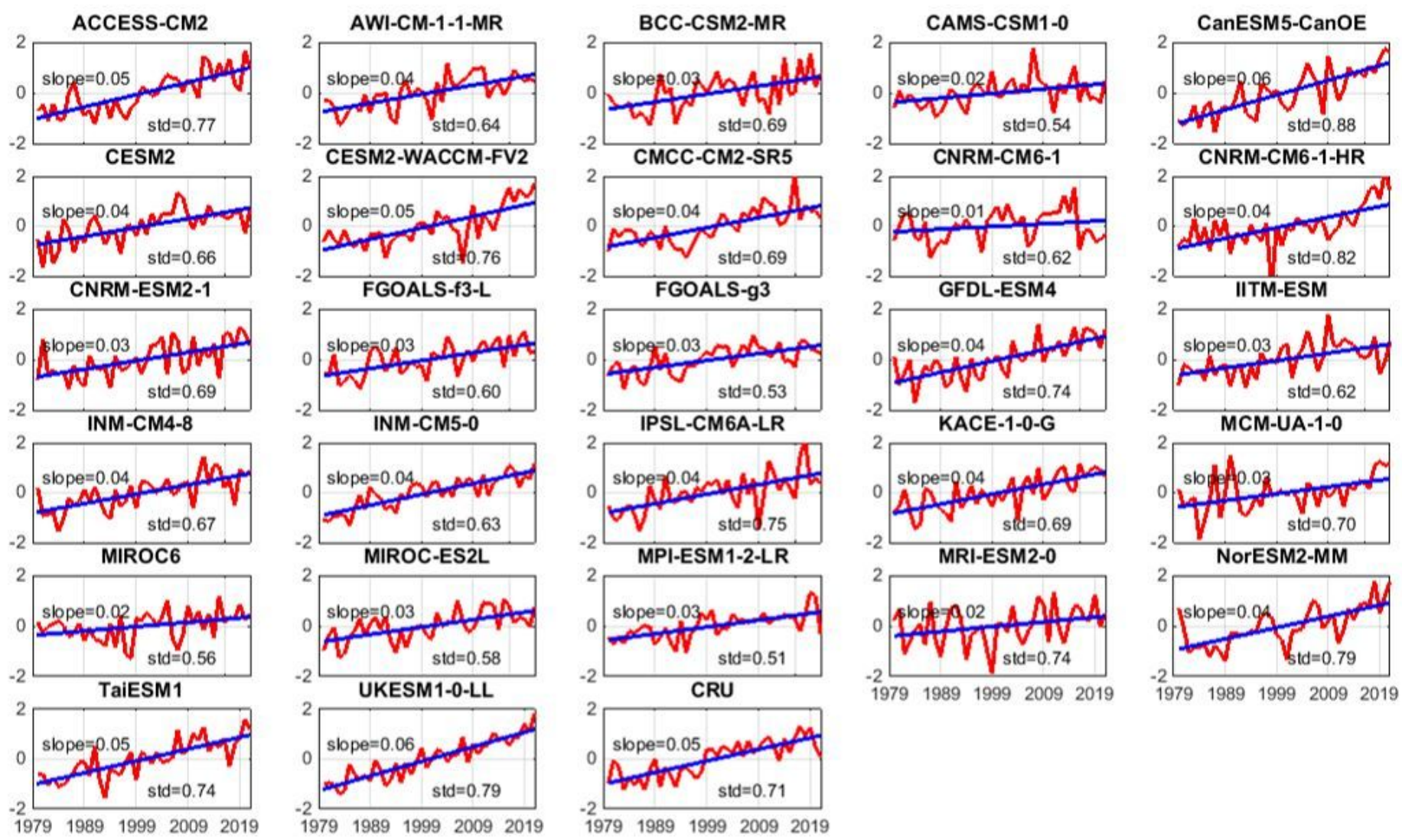

Figure 4

Time series of annual mean of surface air temperature anomalies in twenty-seven CMIP6-GCMs simulations using historical experiment (1979-2020) and the observation (CRU data set). The blue line shows the trend. Standard deviation and the slope of the fitted linear line have been depicted in each subplot. 


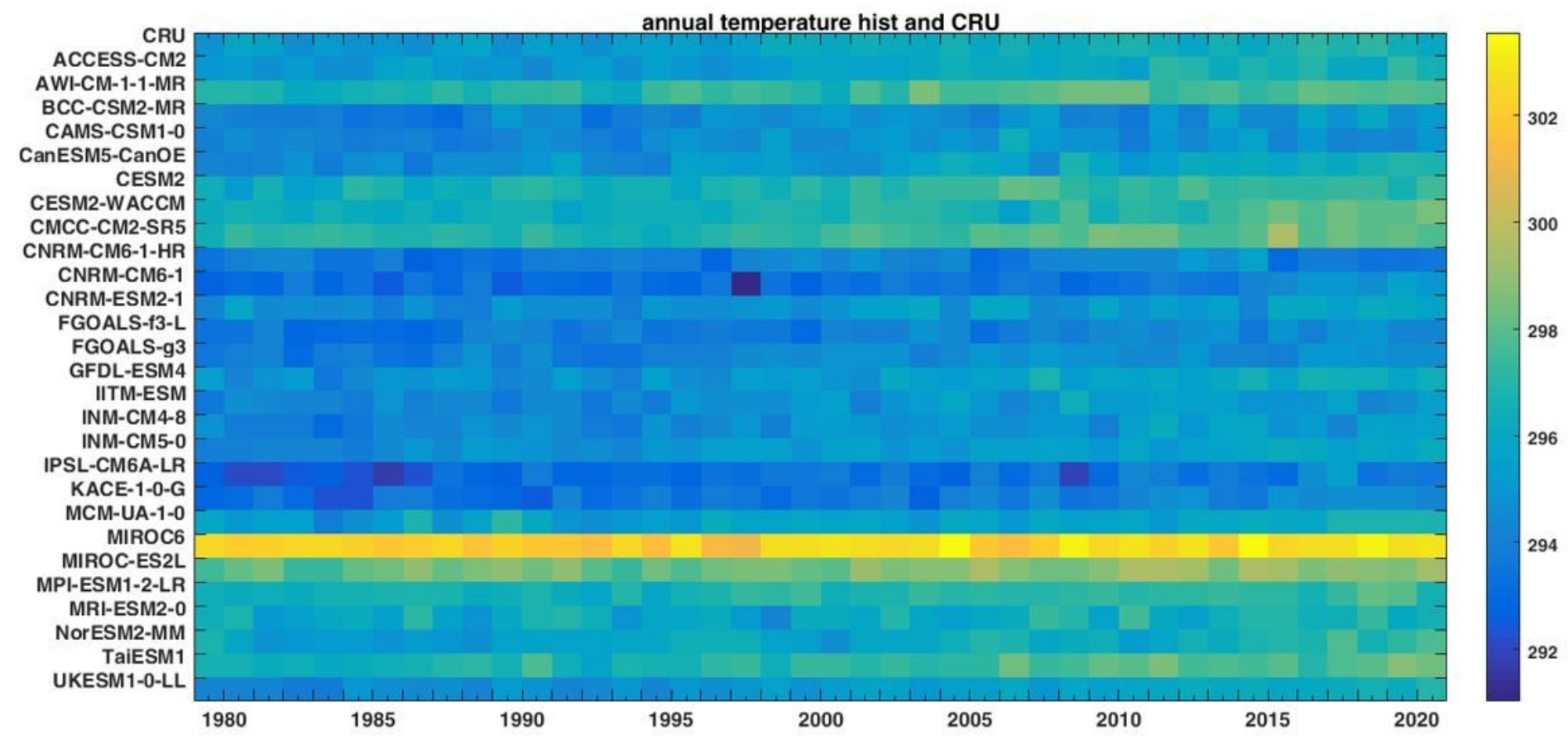

\section{Figure 5}

Annual surface temperature over the area from twenty-seven CMIP6-GCMs historical experiment and CRU data set during 1979-2020. 


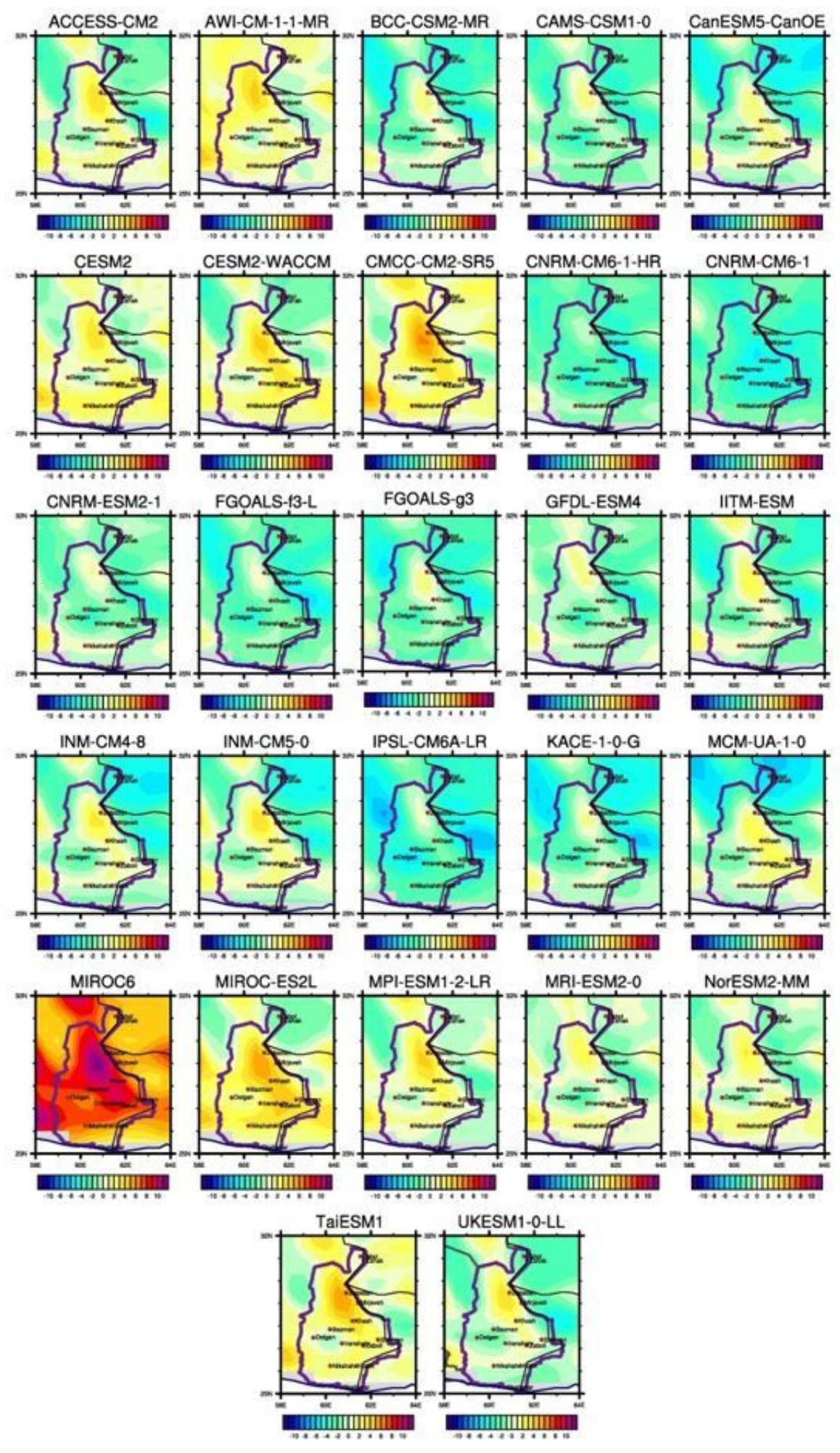

Figure 6

Latitude/longitude distribution of monthly surface air temperature (K) from CMIP6-GCMs (using historical experiment, 1979-2020) minus the values of the CRU data set. The violin, black and blue lines show Sistan-and-Baluchestan Province boundary, country boundary and the northern coast of Oman Sea, respectively. 
(a)

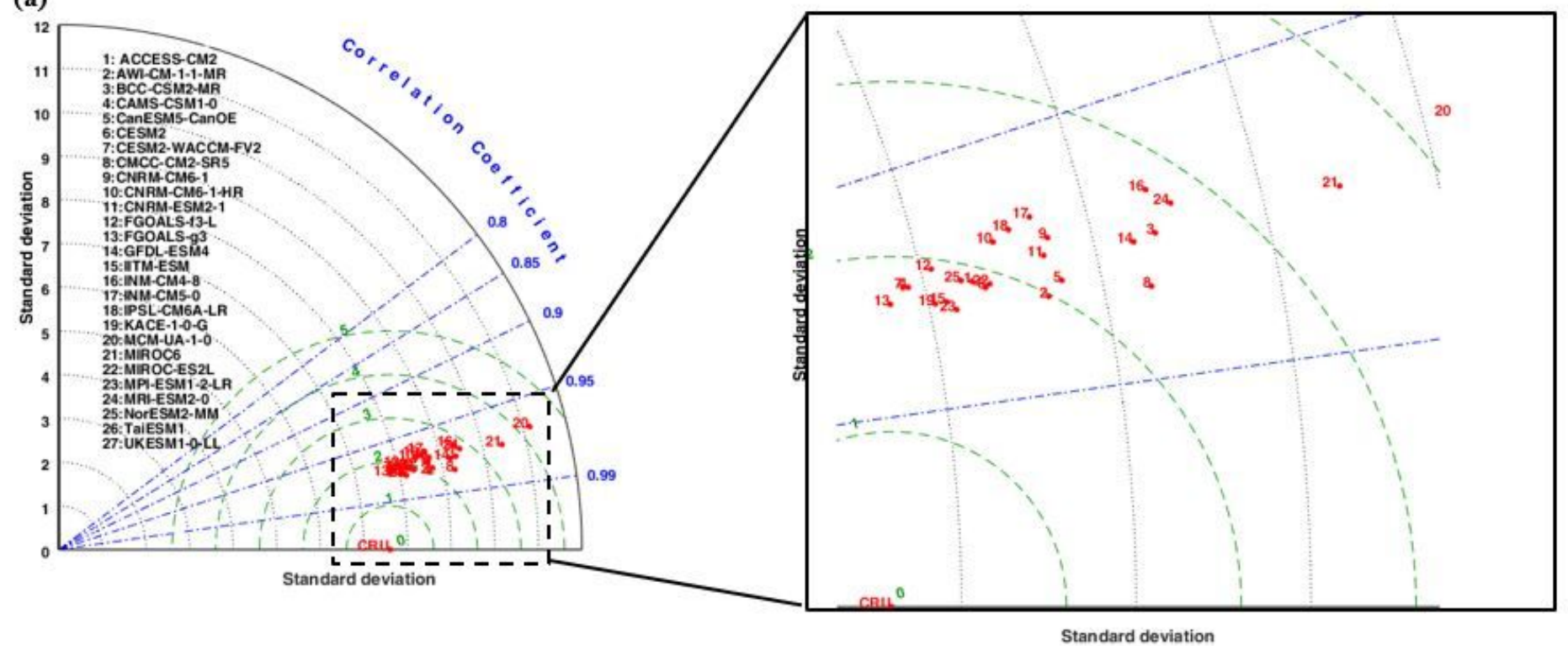

(b)

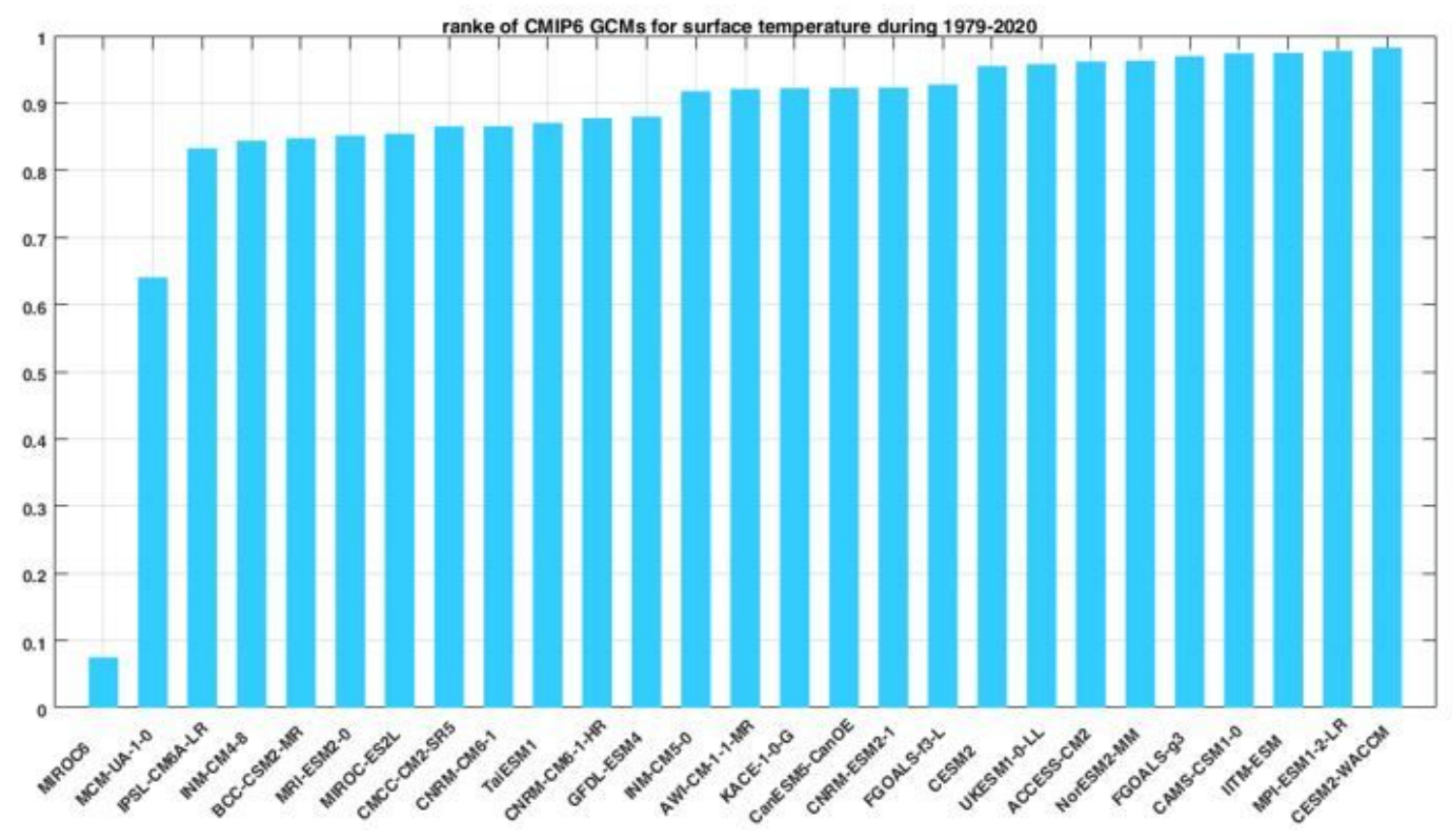

Figure 7

The Taylor diagram of the monthly temperature (K) averaged over the selected area during 1979-2020 using CRU data (Obs) and historical experiment of twenty-seven CMIP6 GCMs.due to their The right subplot is the zoom of the left one. Results of the twenty-sixth and twenty-seventh CMIP6-GCMs could not be fitted to this diagram, $\sigma$ values (9.2 and 8.34), RMSE (2.39 and 1.87) and r (0.97 and 0.97) values, respectively. Rank of CMIP6-GCMs accuracy in determining the surface temperature over the Sistan-andBaluchestan comparing with the CRU data during 1979-2020 (b). 
Violin plot of monthly precipitation (mm) from CMIP6-GCMs using historical experiment during 19792020 and those from CRU data set. Since the horizontal axis is arranged alphabetically, results of the CRU data set have been highlighted in a red-dotted rectangle.

\section{Figure 9}

Annual precipitation over the area from twenty-seven CMIP6-GCMs historical experiment and CRU data set during 1979-2020.
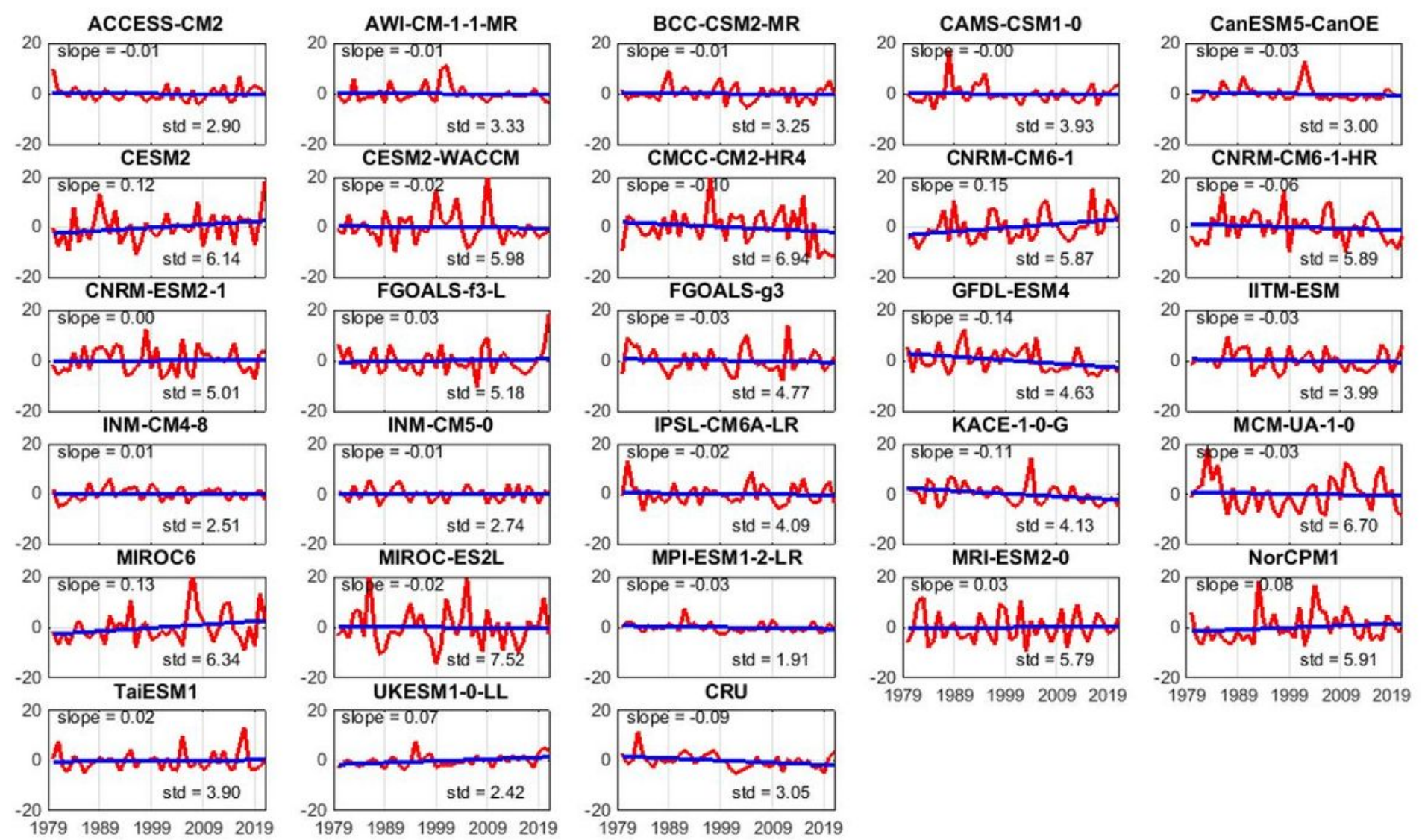

\section{Figure 10}

Time series of annual precipitation anomalies ( $\mathrm{mm} / \mathrm{month}$ ) in twenty-seven CMIP6-GCMs simulations using historical experiment (1979-2020) and the observation (CRU data set). The blue line shows the trend. Standard deviation and the slope of the fitted linear line have been depicted in each subplot.

\section{Figure 11}

Latitude/longitude distribution of precipitation (mm/month) from CMIP6-GCMs (using historical experiment, 1979-2020) minus the values of the CRU data set. The violin, black and blue lines show 
Sistan-and-Baluchestan Province boundary, country boundary and the northern coast of Oman Sea, respectively.

\section{Figure 12}

The Taylor diagram for monthly precipitation $(\mathrm{mm})$ averaged over the selected area during 1979-2020 using CRU data and historical experiment of CMIP6-GCMs (a). Results of the twenty-sixth and twentyseventh CMIP6-GCMs couldn't be fited to this diagram, due to their STD (9.64 and 7.67), RMSE (14.9 and 13. 07) and CC ( 0.95 and 0.20$)$ values, respectively. The rank of CMIP6-GCMs accuary in determining the precipitation over the Sistan-and-Baluchestan comparing with the CRU data during 1979-2020 (b).

\section{Figure 13}

Violin plot of monthly surface air temperature (K) from CMIP6-GCMs using SSP5-8.5 scenario (a) and SSp3-7.0 (b) experiment during 2021-2050. 
(a)
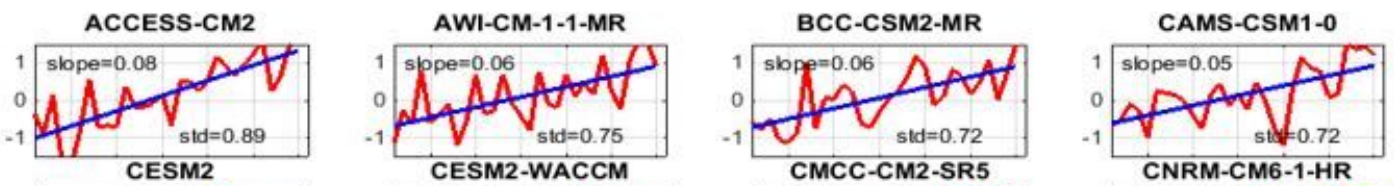

CanESM5-CanOE

slope=0.05 Mats
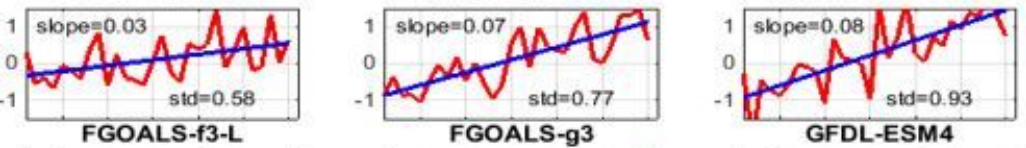

slope $=0.07$ Aff
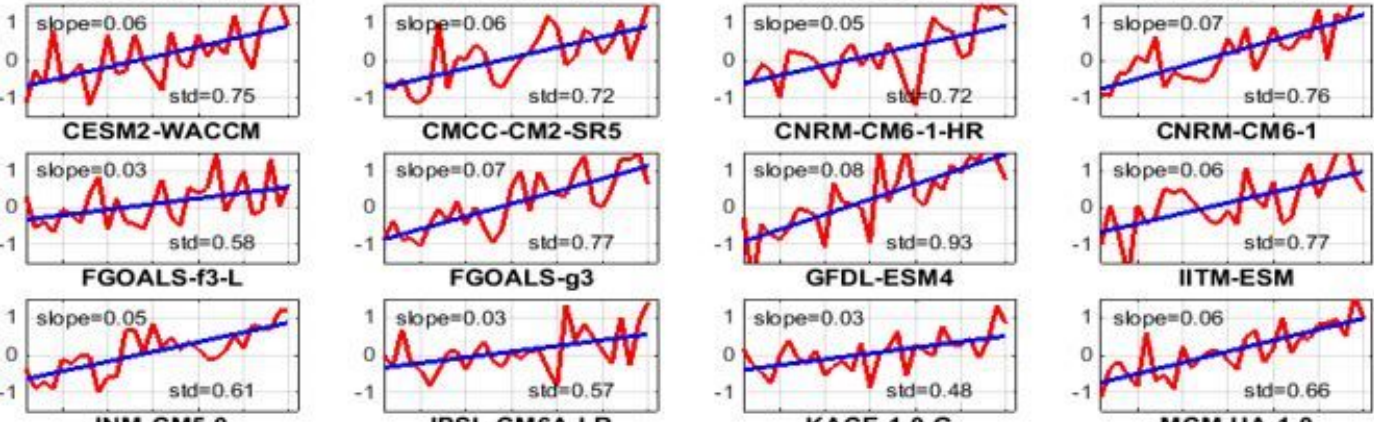

CNRM-CM6-1

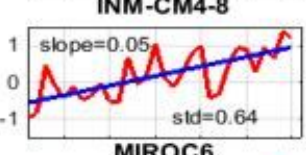

INM-CM5-0
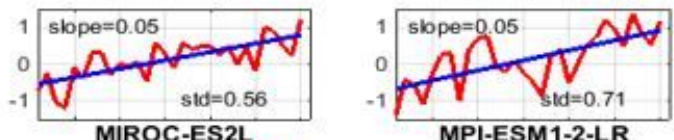

e $=0.07$

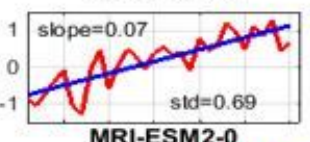

1 siope=0.06 AfAt

1 std $=0.77$
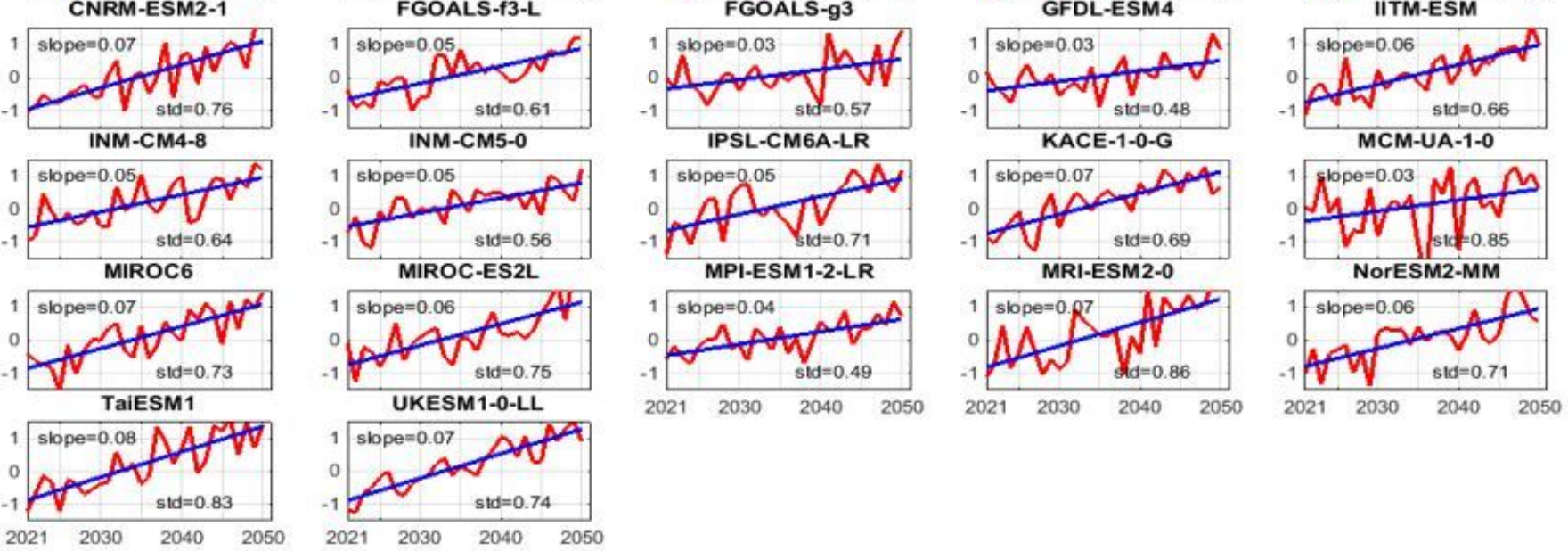

(b)
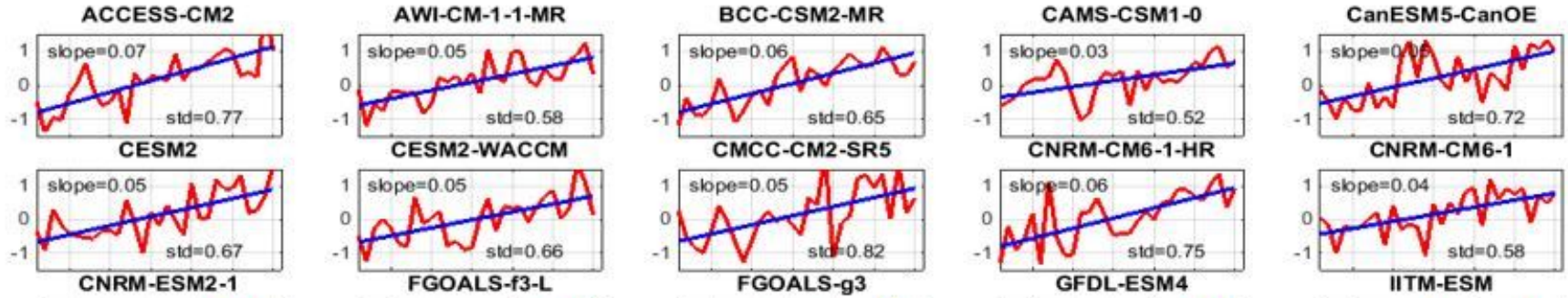

FGOALS-g3
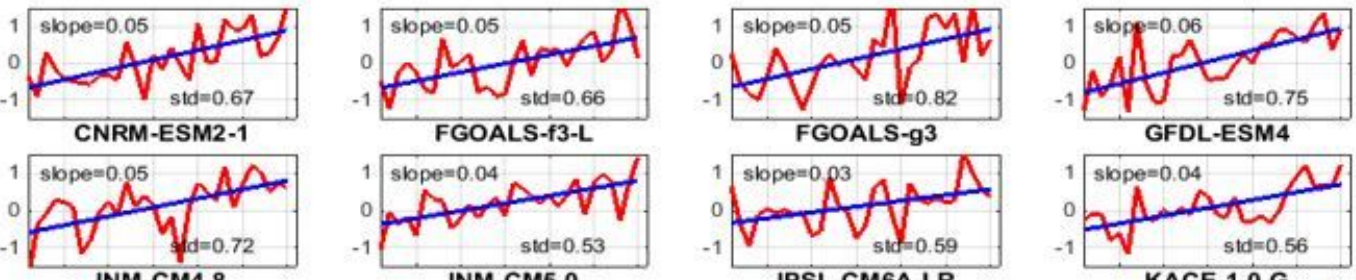
GFDL-ESM4
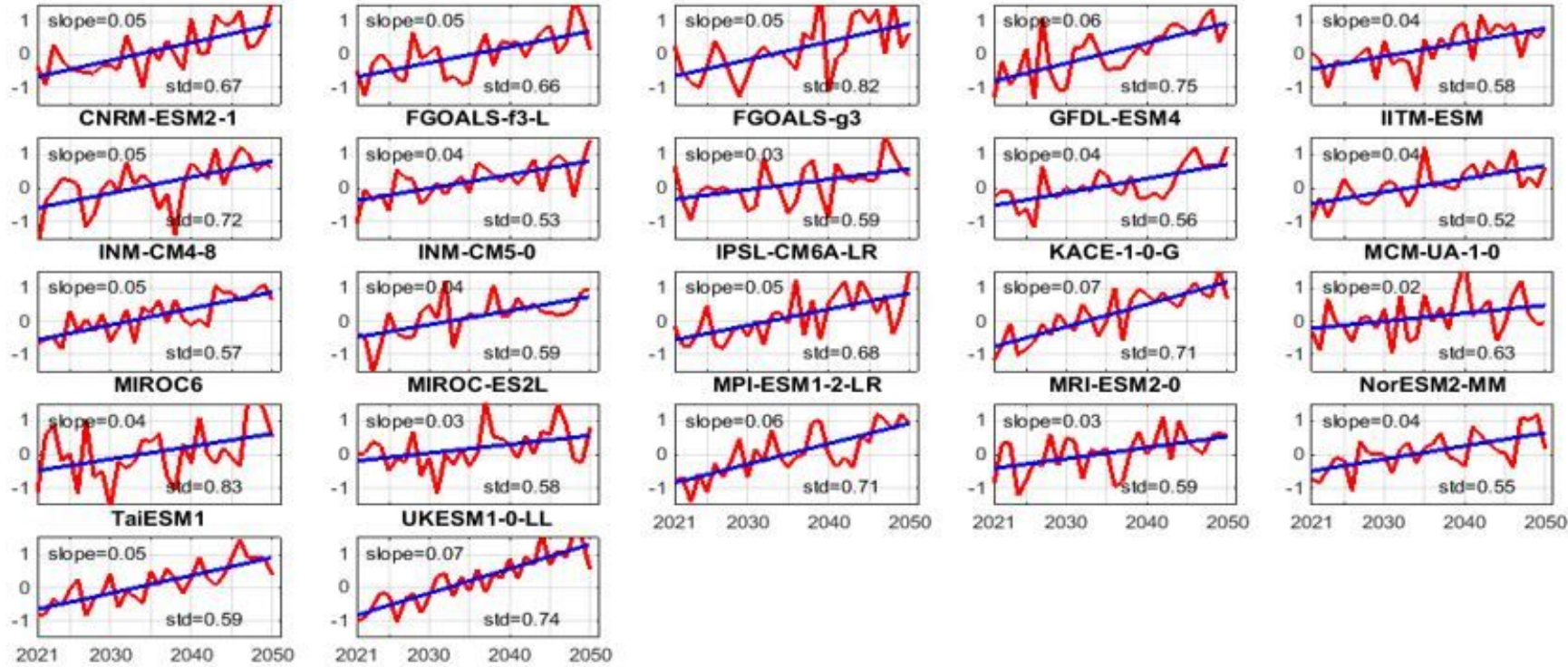

$2021 \quad 2030 \quad 2040 \quad 2050$

$2021 \quad 2030 \quad 2040 \quad 2050$

$2021 \quad 2030 \quad 2040 \quad 2050$

\section{Figure 14}

Time series for the annual mean of anomaly of surface air temperature in twenty-seven GCMs of CMIP6 using SSP5-8.5 (a) and SSP3-7.0 (b) scenarios (2021-2050). The blue lines show the trends. Standard deviation and the slope of the fitted linear line have been depicted in each subplot. 
Figure 15

Horizontal distribution of monthly surface air temperature (K) averaged in the period 2021-2050 using CMIP6-GCMs outputs under SSP5-8.5 scenario. The violin, black and blue lines show Sistan-andBaluchestan Province boundary, country boundary and the northern Coast of Oman Sea, respectively.

\section{Figure 16}

Horizontal distribution of monthly surface air temperature (K) averaged in the period 2021-2050 using CMIP6-GCMs outputs under SSP5-8.5 scenario. The violin, black and blue lines show Sistan-andBaluchestan Province boundary, country boundary and the northern coast of Oman Sea, respectively.

\section{Figure 17}

Violin plot of monthly precipitation (mm) from CMIP6-GCMs using SSP5-8.5 (a) and SSP3-7.0 (b) experiments during 2021-2050. 
(a)
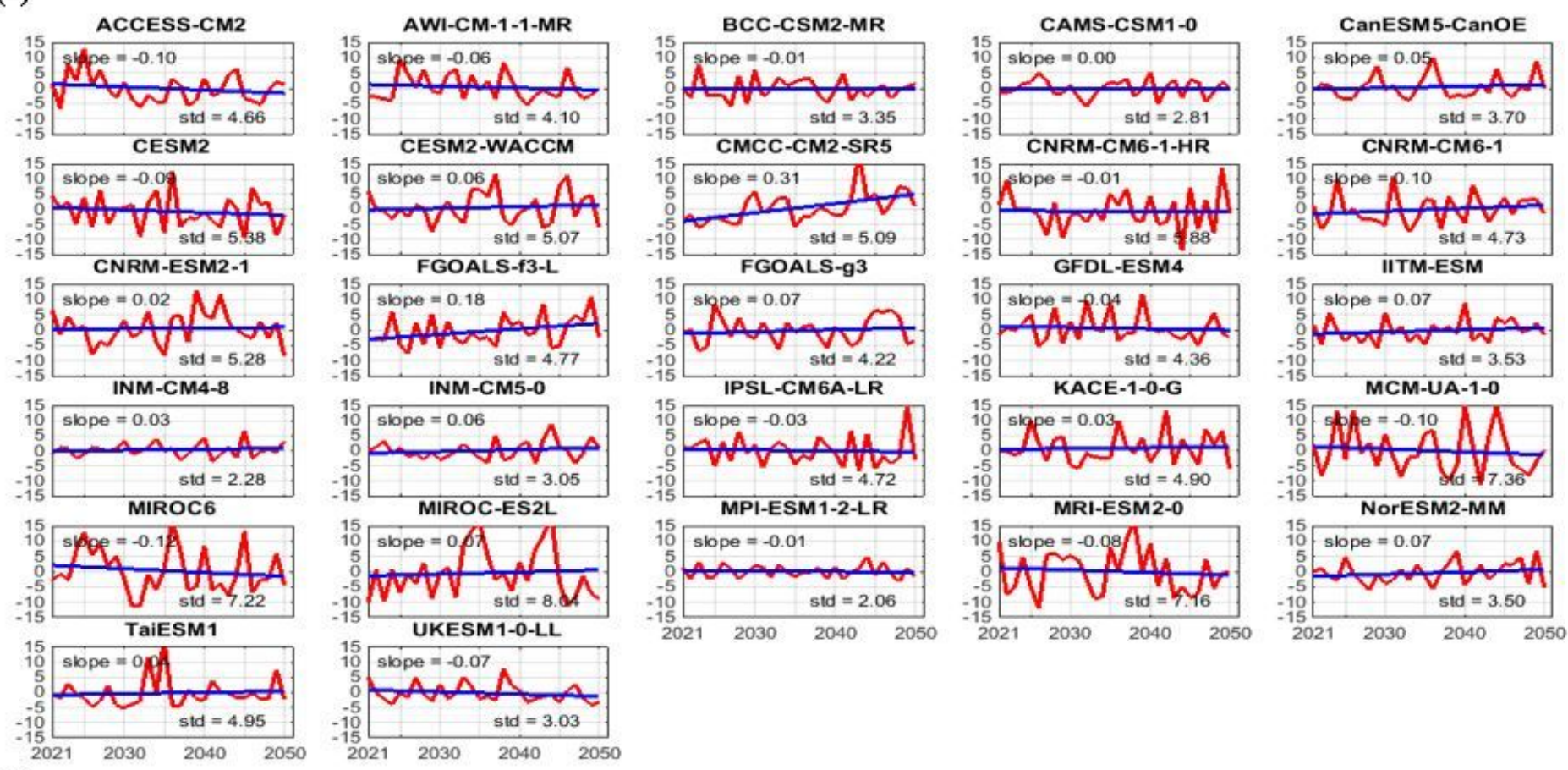

(b)
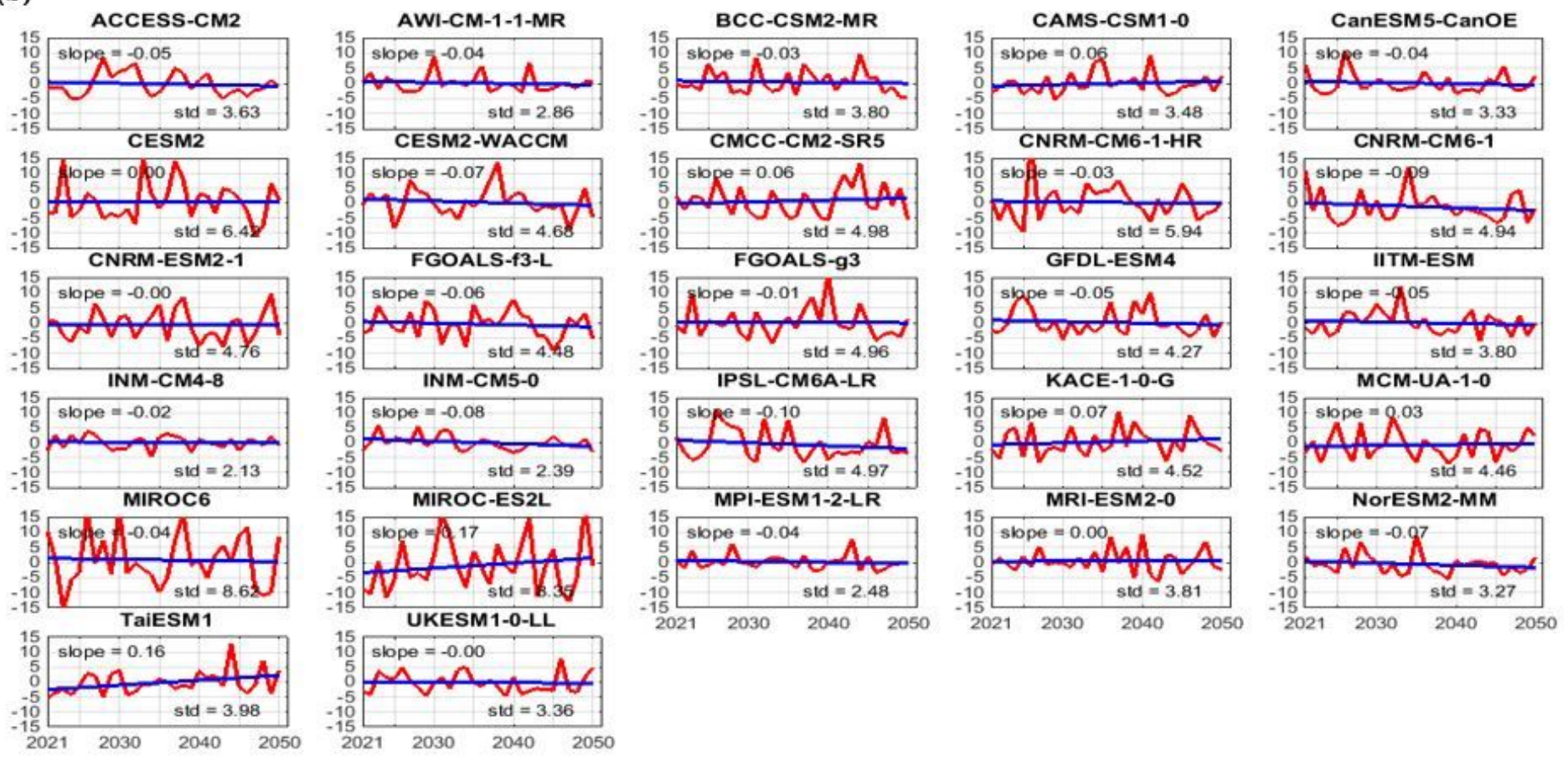

Figure 18

Time series of annual mean of precipitation anomaly in twenty-seven GCMs of CMIP6 simulations using SSP5-8.5 (a) and SSP3-7.0 (b) scenarios (2021-2050). The blue lines show the trends. Standard deviation and the slope of the fitted linear line have been depicted in each subplot. 
Horizontal distribution of monthly precipitation $(\mathrm{mm})$ averaged in the period 2021-2050 using CMIP6GCMs outputs with SSP5-8.5 experiment. The violin, black and blue lines show Sistan-and-Baluchestan Province boundary, country boundary and the northern coast of Oman Sea, respectively.

\section{Figure 20}

Horizontal distribution of monthly precipitation $(\mathrm{mm})$ averaged in the period 2021-2050 using CMIP6GCMs outputs with SSP3-7.0 experiment. The violin, black and blue lines show Sistan-and-Baluchestan Province boundary, country boundary and the northern coast of Oman Sea, respectively. 